\title{
Application of parametric speakers to radio acoustic sounding system
}

\author{
Ahoro Adachi $^{1}$ and Hiroyuki Hashiguchi ${ }^{2}$ \\ ${ }^{1}$ Meteorological Research Institute, Japan Meteorological Agency, 1-1 Nagamine, \\ Tsukuba, Ibaraki 305-0052, Japan \\ ${ }^{2}$ Research Institute for Sustainable Humanosphere, Kyoto University, Gokasho, \\ Uji, Kyoto 611-0011, Japan
}

Correspondence: Ahoro Adachi (aadachi@mri-jma.go.jp)

Received: 10 March 2019 - Discussion started: 10 May 2019

Revised: 1 August 2019 - Accepted: 11 September 2019 - Published: 28 October 2019

\begin{abstract}
In this study, a wind profiler with a radio acoustic sounding system (RASS) and operational radiosonde measurements were used to investigate the technical practicability and reliability of using parametric speakers to measure the vertical profile of virtual temperature. Characteristics of parametric speakers include high directivity and very low side lobes, which are preferable for RASS, especially those operating in urban areas. The experiments were conducted on fine days with light winds to mitigate the effects of the horizontal and vertical components of wind on acoustic waves used for RASS. The results of this study indicated that, although parametric speaker RASS is susceptible to horizontal winds due to the narrower acoustic beam, bias and standard deviation of parametric speaker RASS versus radiosonde virtual temperature difference $\left(0.1^{\circ} \mathrm{C}, 0.4^{\circ} \mathrm{C}\right)$ were close to those from acoustic speakers $\left(0.0^{\circ} \mathrm{C}, 0.4^{\circ} \mathrm{C}\right)$. In addition, when compared with acoustic speaker RASS, the values for the parametric speaker RASS were even smaller $\left(0.1^{\circ} \mathrm{C}, 0.2^{\circ} \mathrm{C}\right)$. Based on these results, it is concluded that the parametric speaker RASS has accuracy and precision comparable with acoustic speaker RASS despite its high directivity of sound.
\end{abstract}

\section{Introduction}

Accurate measurements of temperature are essential in weather forecasting and studies of atmospheric dynamics at all scales. The radio acoustic sounding system (RASS) is a ground-based remote sensing technique that provides verti- cal profiles of virtual temperature from a few hundred meters above the surface up to several kilometers in elevation (Marshall et al., 1972; Peters et al., 1985). The RASS technique has been applied to wind profilers, whereby vertical profiles of virtual temperature can be measured with the same temporal and spatial resolution that the profiler uses to measure winds (e.g., Adachi et al., 2005) with a relatively high degree of reliability (Matuura et al., 1986; Moran et al., 1991; Angevine and Ecklund, 1994).

When using RASS techniques, one or more acoustic sources are co-located with an antenna, and the profiler provides the vertical profile of the speed at which the acoustic disturbance propagates vertically (Angevine et al., 1994). RASS temperature measurements can be obtained on the basis of the relationship between the virtual temperature $T_{\mathrm{V}}$ $\left({ }^{\circ} \mathrm{C}\right)$, the local speed of sound $C_{\mathrm{a}}\left(\mathrm{m} \mathrm{s}^{-1}\right)$, and the measured radial wind speed $w\left(\mathrm{~m} \mathrm{~s}^{-1}\right)$, and a good approximation can be obtained by

$T_{\mathrm{v}}=\left(\frac{C_{\mathrm{a}}-w}{20.047}\right)^{2}-273.15$.

Thus, a vertical profile of the speed of sound can be converted to a profile of virtual temperature. The radial wind speed is considered in Eq. (1) because the neglect of the wind velocity along the beam may be the largest source of error in RASS measurements (e.g., May et al., 1989; Angevine et al., 1994). However, we could not consider the radial wind speed in our experiments because strong clutter sometimes contaminated the Doppler spectrum and masked the atmospheric echo in 
the vertical beam observation. This issue is addressed in later sections.

The systematic error or bias of the virtual temperature measurements from RASS observations has been shown to be less than $1^{\circ} \mathrm{C}$, while the standard deviation or precision has also been reported around $1{ }^{\circ} \mathrm{C}$. May et al. (1989) compared virtual temperatures obtained from 915 and $50 \mathrm{MHz}$ RASS with those obtained from radiosonde measurements. The RASS data were averaged over approximately $6 \mathrm{~min}$, and about 50 soundings covering both the summer and winter seasons were examined. Both the bias and the standard deviation were about $1{ }^{\circ} \mathrm{C}$, even without the application of the vertical velocity correction. On the other hand, Martner et al. (1993) assessed the performance of 915,404 , and $50 \mathrm{MHz}$ wind profilers with RASS by comparing with about 150 radiosonde measurements. They found that the bias (standard deviation) was less than $0.3^{\circ} \mathrm{C}$ (about $1^{\circ} \mathrm{C}$ ) for most systems, even though they did not make the correction for vertical air motions, as the comparison was made under low vertical wind conditions. Moran and Strauch (1994) compared temperature profiles obtained using a very high-frequency (VHF) wind profiler with RASS with those obtained from radiosondes during a 5 -week period. They reported that the accuracy (standard deviation) was $0.9^{\circ} \mathrm{C}$ (less than $1^{\circ} \mathrm{C}$ ), after the application of the vertical velocity correction. Moreover, Angevine et al. (1998) compared the virtual temperature measured by a $915 \mathrm{MHz}$ wind profiler with RASS with in situ observations at $396 \mathrm{~m}$ above ground level (a.g.l.) on a tower. They found that the precision of the RASS measurements was less than $0.9 \mathrm{~K}$ after the application of the vertical velocity correction and corrections for thermodynamic constants. In addition, Görsdorf and Lehmann (2000) reported that the bias (standard deviation) of the RASS measurements with a $1.3 \mathrm{GHz}$ wind profiler is $0.1 \mathrm{~K}(0.7 \mathrm{~K})$ from the data observed for a year compared with radiosondes if accurate corrections for vertical velocity, range, and thermodynamic constants were applied. On the other hand, the height coverage of RASS depends on the radio wave frequency deployed (May et al., 1988; Martner et al., 1993) but is also limited by both the advection of the sound wave with the horizontal wind and the atmospheric attenuation of the acoustic signal in addition to the effects of turbulence and vertical temperature gradients (Lataitis, 1992).

A wind profiler with RASS has been frequently used to study the dynamics of the atmosphere, especially in the boundary layer (e.g., Neiman et al., 1992; Peters and Kirtzel, 1994; May, 1999; Bianco and Wilczak, 2002; White et al., 2003; Adachi et al., 2004; Hashiguchi et al., 2004; Chandrasekhar Sarma et al., 2008). Among the limitations of this method, an important one is the emission of strong sound waves, whose frequency cannot be arbitrarily selected but determined by the wavelength of the radio wave used by the profiler to match the Bragg condition (the acoustic wavelength $\lambda_{\mathrm{a}}$ is equal to half the electromagnetic wavelength $\left.\lambda_{e}\right)$. Although the acoustic speakers used for RASS measure- ments are usually co-located with the antenna and directed vertically so that the generated sound wave propagates along the radio wave, a large portion of the sound wave leaks horizontally because of the side lobes of the speakers, which prevents the temporal and/or continuous operation of RASS in urban environments (Wulfmeyer et al., 2015). Thus, a new type of speaker that has extremely low side lobes would be ideal for RASS measurements.

A theoretical study of parametric speakers (or parametric acoustic array, PAA) was established by Westervelt (1963). That study revealed that the nonlinear interaction between two collimated high-frequency sound beams in an ideal fluid medium produces two new waves with a sum and difference frequencies, and the latter may be used to produce narrow beams of sound at relatively low frequencies in the audible range. Berktay and Leahy (1974) presented a theoretical description that can be used to compute the far-field response of a parametric array for multiple sets of parameters. Thereafter, the use of parametric arrays underwater has been the subject of a number of theoretical and experimental studies. On the other hand, an experimental investigation of the parametric array in air was first demonstrated by Bennett and Blackstock (1975), and recently the parametric loud speaker has become available for audio and speech applications (Gan et al., 2012). The properties of parametric speakers include high directivity and very low side lobes, which are preferable for RASS measurements. However, to the best of our knowledge, there are few, if any, studies on RASS techniques using this type of speaker.

In this study, a detailed evaluation of the parametric speaker for RASS measurements was conducted by comparing temperature data derived from this type of speaker and those from both radiosonde and acoustic speaker RASS at the Meteorological Research Institute (MRI) field site in Tsukuba, Japan. Instrumentation and data analysis techniques are presented in Sect. 2. Results are presented in Sect. 3 and discussed in Sect. 4. Finally, a summary of our conclusions is presented in Sect. 5.

\section{Instrumentation and data analysis techniques}

The MRI wind profiler, a four-panel LAP-3000 with RASS (Fig. 1a), is the type originally developed at the National Oceanic and Atmospheric Administration (NOAA) Aeronomy Laboratory (Carter et al., 1995; Ecklund et al., 1988). The profiler used in this study operated at $1357.5 \mathrm{MHz}$ with $100 \mathrm{~m}$ pulse lengths and a minimum (maximum) gate of $200 \mathrm{~m}(1300 \mathrm{~m})$ from the antenna in RASS mode. The vertical resolution was set to $100 \mathrm{~m}$ based on the requirements for the Global Climate Observing System (GCOS) Reference Upper-Air Network (GRUAN) by the WMO (2007). The effect of the vertical air motion was not considered for RASS measurements in the experiments because strong clutter caused by automobiles on a nearby highway sometimes 


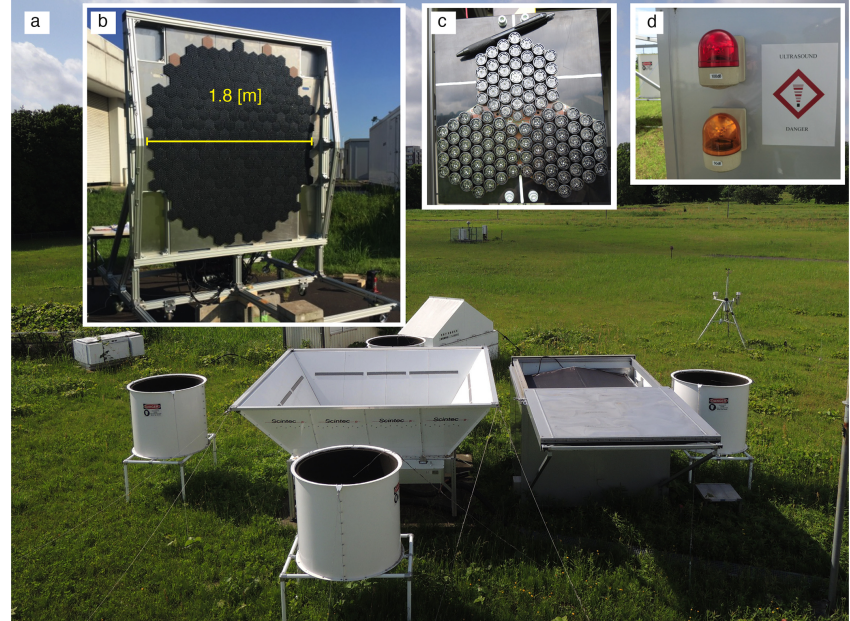

Figure 1. Pictures of (a) LAP-3000 with acoustic speakers and a parametric speaker for RASS, (b) overview on a support frame, (c) partial expanded view of the parametric speaker, and (d) rotary warning lights on the shed wall. The parametric speaker mounted on top of the shed with a sliding roof is covered with rainproof film in the field, as shown in (a).

contaminated the Doppler spectrum and masked the atmospheric echo (Adachi et al., 2004).

The configuration and operating parameters of the wind profiler with RASS are summarized in Table 1. The antenna of the profiler was co-located with four acoustic speakers in cylindrical enclosures and a parametric speaker, which was mounted on top of a shed (Fig. 1a). For the experiment, the RASS measurements were carried out continuously for about an hour without wind observations. Since the wind profiler operated at $1.3 \mathrm{GHz}$, the frequency of the acoustic source for the RASS measurement was set at about $3 \mathrm{kHz}$ to match the Bragg condition. Prior to every experiment, an acoustic wave with a wide frequency range (2715 to $3265 \mathrm{~Hz}$ corresponding to about $\pm 50^{\circ} \mathrm{C}$ ) was generated to detect center Doppler frequency of the RASS echo. Then, during each experiment, the emitted acoustic frequency range was automatically narrowed down to a shorter frequency span $(130 \mathrm{~Hz}$, corresponding to about $\pm 12{ }^{\circ} \mathrm{C}$ ) around the detected center frequency to increase signal-to-noise ratio (SNR) and height coverage. The frequency sweeps were randomly shuffled within each frequency range to make the acoustic spectrum almost uniform (Angevine et al., 1994).

The MRI parametric speaker, 100FM-001, consists of an array of more than 10000 piezoelectric ceramic transducers configured on a semicircular board with a diameter of $1.8 \mathrm{~m}$ (Fig. 1b). The transducers were divided into 278 segments, with each one mounted on the hexagonal board (Fig. 1c). The field programmable gate array (FPGA) modules in the speaker system were used to control the phase of the signals fed into the segments to generate the acoustic beam with a particular preferred width and direction like other PAAs (e.g.,
Table 1. Parameters of the wind profiler with RASS.

\begin{tabular}{ll}
\hline Frequency & $1357.5 \mathrm{MHz}$ \\
Peak power & $500 \mathrm{~W}$ \\
Beam width & $<7^{\circ}$ \\
Beam elevation & $90^{\circ}$ \\
Pulse width & $665 \mathrm{~ns}$ \\
First range gate & $200 \mathrm{~m}$ \\
Last range gate & $1300 \mathrm{~m}$ \\
Gate spacing & $100 \mathrm{~m}$ \\
Interpulse period & $12163 \mathrm{~ns}$ \\
Coherent integration & 3 \\
Spectra averaged & 191 \\
Number of fast Fourier & 8192 \\
transform (FFT) points & \\
Acoustic source & Pseudo-random frequencies \\
& (random hop) \\
Location & $36^{\circ} 03^{\prime} 19^{\prime \prime} \mathrm{N}, 140^{\circ} 07^{\prime} 28^{\prime \prime} \mathrm{E}$ \\
Manufacture & Scintec \\
Model & LAP-3000 $^{\prime}$
\end{tabular}

Table 2. Characteristics of the MRI parametric speaker.

\begin{tabular}{|c|c|}
\hline Center frequency & $40.0 \pm 1.0 \mathrm{kHz}$ \\
\hline Band width $(-6 \mathrm{~dB})$ & $<2.0 \mathrm{kHz}$ \\
\hline Sound pressure level & $\begin{array}{l}>200 \mathrm{~dB} \text { (at } 0.3 \mathrm{~m}, 40 \mathrm{kHz} \text {, } \\
\text { theoretical value) }\end{array}$ \\
\hline Number of transducers & 10008 \\
\hline Number of channels & 278 \\
\hline Beam width & $5-17^{\circ}\left(1^{\circ}\right.$ step $)$ \\
\hline Beam elevation & $60-90^{\circ}\left(1^{\circ}\right.$ step $)$ \\
\hline Beam azimuth & $0-359^{\circ}\left(1^{\circ}\right.$ step $)$ \\
\hline Input audio signal freq. & $2.8-3.3 \mathrm{kHz}$ \\
\hline Speaker diameter & $1.8 \mathrm{~m}$ \\
\hline Speaker system size & $2.1 \times 2.1 \times 1.8 \mathrm{~m}$ \\
\hline Manufacture & Starlite Co., Ltd. \\
\hline Model & 100FM-001 \\
\hline
\end{tabular}

Wu et al., 2012). The configuration and operating parameters of the speaker are summarized in Table 2.

One of the desirable features of the PAA for RASS measurements is high directivity of the sound beam. Prior to the designing of the MRI PAA, we performed a preliminary field sensitivity test for RASS using a prototype PAA with a beam width smaller than $2^{\circ}$ and relatively small power, but no RASS echo was observed. We modified the prototype to broaden the beam width to about $6^{\circ}$ or more, and the RASS echo was observed up to a few range gates. We concluded that too narrow of a beam is not good for the RASS observation, and the PAA beam width should match that of the profiler radio wave. Because the beam width of the MRI profiler is less than $7^{\circ}$ (Table 1), the default sound beam width of the speaker was designed to be $5^{\circ}$ (Table 2). Although the latter width is somewhat smaller than that of the former, the RASS focal spot determined by the sound beam width may 


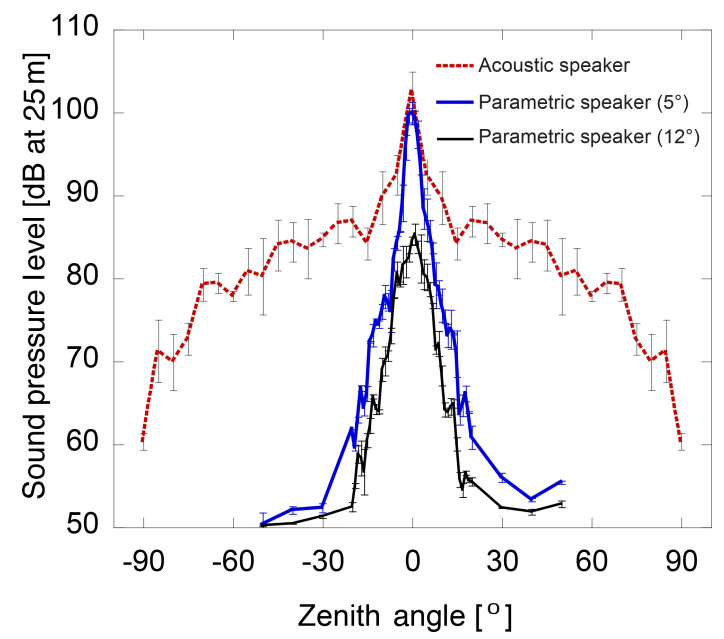

Figure 2. Audible sound pressure level (SPL) pattern for an acoustic speaker (red), the parametric speaker with the measured beam width of $5^{\circ}$ (blue) and $12^{\circ}$ (black) at a frequency of $3 \mathrm{kHz}$. The error bars represent $2 \sigma$. The SPL pattern for the acoustic speaker in the negative zenith angle region is a mirror image of the pattern measured at the positive zenith angle for ease of viewing. The background noise level was about $50 \mathrm{~dB}$. The SPL was measured with a sound level meter (Rion NL-42).

be broadened by turbulence (Lataitis, 1992) and match the radio beam width, which is preferable for RASS measurements.

In order to measure the audible sound pressure level (SPL) pattern, we installed the PAA on a standing frame (Fig. 1b) for temporal use to radiate sound horizontally. The measurements were made on fine (no rain) days under calm wind $\left(<2 \mathrm{~m} \mathrm{~s}^{-1}\right)$ with a sound level meter set at a distance of $25 \mathrm{~m}$ because a range of $10 \mathrm{~m}$ would be necessary to completely produce audible sound from ultrasound with a PAA of this size (Tomoo Kamakura, personal communication, 2018). Safety was also considered for the level-meter operators in determining the distance, as is discussed later. The PAA was installed on top of a shed after the measurements (Fig. 1a). The audible sound pressure level (SPL) pattern (Fig. 2) measured in the field indicated that the PAA exhibited high directivity and low side lobes, as expected; the SPL was less than $55 \mathrm{~dB}(\mathrm{dBA})$ at a zenith angle of $40^{\circ}$, which was close to the value of the background noise level of $50 \mathrm{~dB}$ despite the fact that the peak power $(100 \mathrm{~dB})$ was close to that of an acoustic speaker $(105 \mathrm{~dB})$. By contrast, for the acoustic speaker, the SPL was as high as $70 \mathrm{~dB}$ even at a zenith (elevation) angle of $85^{\circ}\left(5^{\circ}\right)$ and is therefore significantly more annoying to the ear than a PAA.

To evaluate the parametric speaker for RASS measurements, temperature data derived from the PAA-RASS were compared with values derived both from radiosonde and from the acoustic speaker RASS. The dwell time for each RASS measurement was set at about $57 \mathrm{~s}$ followed by an intermediate cessation operation time of $3 \mathrm{~s}$, in which the two speaker systems were alternately switched every minute for comparison. Each RASS data set obtained with the two speaker systems was independently processed with quality control to confirm the consistency in the height and time field values.

The profiles of virtual temperature derived from operational radiosonde measurements were used as the standard reference data for comparison. The radiosondes (the Meisei RS-11G used until September 2017, followed by the Meisei iMS-100; Kizu et al., 2018) were launched from the Aerological Observatory, which is located about $400 \mathrm{~m}$ northeast of the profiler (for the layout of the relative locations, see Adachi et al., 2004). The time resolution of the radiosonde data used for the comparison was $1 \mathrm{~s}$, which corresponded to the height resolution of about $6 \mathrm{~m}$. The radiosondes were launched operationally at 08:30 JST (Japan standard time: JST $=$ UTC $+9 \mathrm{~h}$ ), and most of the RASS experiments included the launch time (Table 3). The RASS data were taken during morning hours, on fine (no rain) days, with light winds $\left(<3 \mathrm{~m} \mathrm{~s}^{-1}\right.$ at $20 \mathrm{~m}$ a.g.l.), mostly in autumn, when the region was under the influence of a high-pressure system. In the radiosonde comparison, the RASS data were averaged over about an hour for each experiment to mitigate both the effects of vertical velocity (Angevine and Ecklund, 1994; Görsdorf and Lehmann, 2000) and the spatial difference between the radiosonde and the profiler with RASS. Contrastingly, the 1 min raw RASS data were used to compare the two speaker systems.

\section{Results of comparison}

\subsection{Applicability of parametric speaker to RASS}

As there are few, if any, studies on RASS using parametric speakers, preliminary experiments were first conducted to confirm whether the secondary audible waves produced by this type of speaker can propagate long distances along the radio wave while satisfying the Bragg condition before evaluating it for RASS application. The MRI PAA radiates bifrequency primary waves that are around 37 and $40 \mathrm{kHz}$ from all the transducers simultaneously to generate the parametric sound of the secondary difference frequency, which was around $3 \mathrm{kHz}$ for RASS. Since sound absorption generally increases with frequency, the ultrasound may be substantially dissipated as altitude increases, although the peak SPL of the ultrasonic sound close to the PAA (Table 2) was about $100 \mathrm{~dB}$ larger than that of audible sound generated by the acoustic speaker (Fig. 2). The atmospheric absorption is a function of the sound frequency, temperature, humidity, and pressure of the air (ISO, 1993). Example profiles of the sound attenuation coefficient and attenuation at 3 and $40 \mathrm{kHz}$ derived from radiosonde measurements are shown in Fig. 3. In the derivation, only the effect of atmospheric ab- 
Table 3. List of the comparison experiments, including date, period, sea level pressure, surface temperature, surface wind speed, and mean wind speed aloft (20-1200 m a.g.1.) with standard deviation. Means and standard deviations are not vector but scalar statistics.

\begin{tabular}{llrrrr}
\hline Date & Time $(\mathrm{JST})$ & $P_{\text {sea }}(\mathrm{hPa})$ & $T\left({ }^{\circ} \mathrm{C}\right)$ & $U\left(\mathrm{~m} \mathrm{~s}^{-1}\right)$ & $\bar{U}_{\text {aloft }}\left(\mathrm{m} \mathrm{s}^{-1}\right)$ \\
\hline 14 Oct 2016 & $08: 03-09: 00$ & 1023.0 & 15.0 & 2.0 & $5.8 \pm 2.8$ \\
15 Oct 2016 & $08: 01-09: 00$ & 1025.5 & 15.8 & 1.4 & $2.1 \pm 0.5$ \\
19 Oct 2016 & $08: 01-09: 00$ & 1015.6 & 20.2 & 3.1 & $5.4 \pm 1.7$ \\
21 Oct 2016 & $08: 01-09: 00$ & 1016.5 & 15.7 & 2.1 & $3.1 \pm 0.7$ \\
24 Oct 2016 & $08: 19-09: 00$ & 1014.9 & 13.1 & 2.0 & $3.2 \pm 1.5$ \\
27 Oct 2016 & $08: 37-09: 32$ & 1016.1 & 18.8 & 0.8 & $1.6 \pm 0.6$ \\
28 Oct 2016 & $08: 03-09: 00$ & 1018.4 & 12.5 & 1.2 & $7.6 \pm 3.3$ \\
31 Oct 2016 & $08: 09-09: 00$ & 1024.3 & 12.7 & 1.7 & $5.4 \pm 2.6$ \\
2 Nov 2016 & $08: 25-09: 02$ & 1023.2 & 9.8 & 1.6 & $5.0 \pm 2.3$ \\
8 Nov 2016 & $08: 03-09: 02$ & 1017.0 & 7.4 & 2.2 & $5.4 \pm 3.4$ \\
12 Nov 2016 & $08: 09-09: 06$ & 1019.8 & 11.8 & 0.4 & $3.7 \pm 1.3$ \\
30 Nov 2016 & $09: 11-09: 32$ & 1030.4 & 5.7 & 1.8 & $2.9 \pm 1.4$ \\
29 Mar 2017 & $08: 43-09: 00$ & 1020.0 & 8.4 & 2.4 & $4.9 \pm 1.3$ \\
9 Aug 2017 & $08: 45-09: 00$ & 991.3 & 30.5 & 1.2 & $4.5 \pm 2.5$ \\
7 Sep 2017 & $08: 01-09: 00$ & 1003.2 & 22.3 & 1.8 & $2.3 \pm 0.5$ \\
9 Apr 2018 & $08: 25-09: 02$ & 1013.6 & 10.2 & 1.6 & $6.9 \pm 5.1$ \\
\hline
\end{tabular}

sorption related to viscosity and thermal conductivity of the air, molecular relaxation of rotation, and vibration of $\mathrm{O}_{2}$ and $\mathrm{N}_{2}$ was considered (see Appendix), and other physical effects (e.g., reflection from the surface; ISO, 1996) were disregarded. Figure $3 \mathrm{a}$ shows that the attenuation for the audible wave of $3 \mathrm{kHz}$ propagating from the surface to an altitude of $1 \mathrm{~km}$ a.g.l. was $14.7 \mathrm{~dB}$, which indicated that the sound wave at this frequency with an SPL of $105 \mathrm{~dB}$ on the ground decreased to $90.3 \mathrm{~dB}$ at this altitude. By contrast, this figure also suggests that the sound wave at $40 \mathrm{kHz}$ with an SPL of $200 \mathrm{~dB}$ generated on the ground was reduced to less than $0 \mathrm{~dB}$ at $160 \mathrm{~m}$ a.g.l. Thus, the primary wave of the PAA was not expected to reach beyond this altitude. However, the difference-frequency component could propagate to a higher altitude because it was audible sound.

Figure 4 shows a set of spectra obtained with the acoustic speakers and the PAA at the time when the radiosonde measurement in Fig. 3 was made. The plots were obtained by the LAP-XM, which is a software program developed on the basis of the Profiler On-line Program (POP; Carter et al., 1995). The RASS echoes associated with the acoustic speakers were obtained from altitudes as high as $1.3 \mathrm{~km}$ a.g.l. On the other hand, those associated with the PAA were obtained from an altitude of $1.1 \mathrm{~km}$ a.g.l. Although the PAA-RASS height coverage was somewhat lower than that associated with acoustic speakers, this was much higher than the altitude where the primary ultrasound waves were expected to dissipate. This result suggests that the secondary difference-frequency component may reach the altitude comparable with the audible wave generated by acoustic speakers while satisfying the Bragg condition and propagating along the radio wave as an audible wave. The height coverage of the two speaker systems is discussed later.

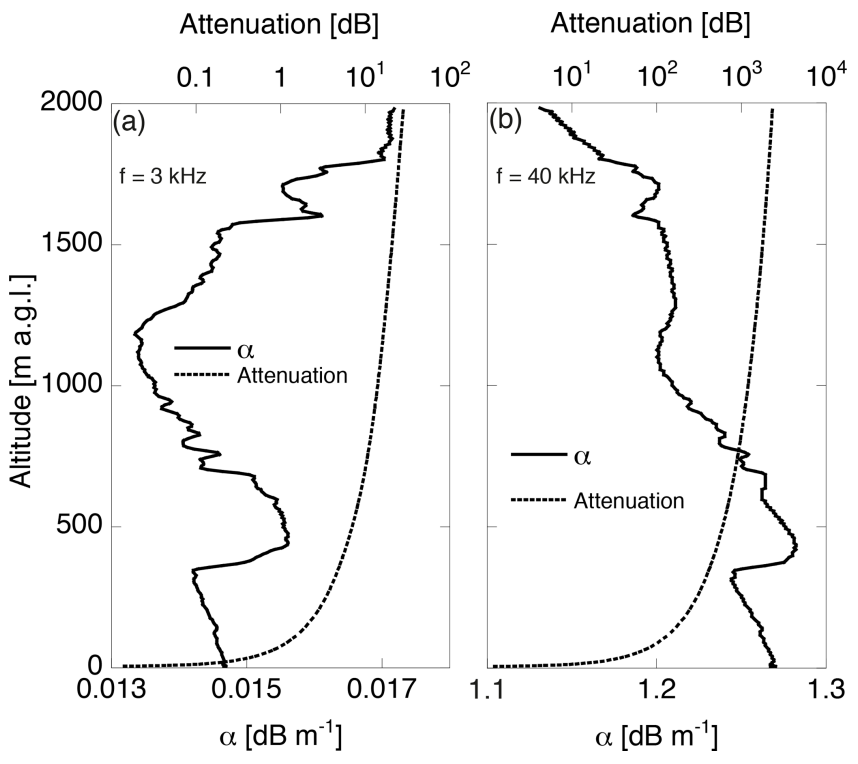

Figure 3. Profiles of atmospheric-attenuation coefficient $\alpha$ and atmospheric attenuation for sound at frequencies of (a) 3 and (b) $40 \mathrm{kHz}$ derived from the radiosonde measurements at 08:30 JST on 19 October 2016, at the MRI site.

Another conformity of the secondary audible wave formed by the PAA to the sound wave by the acoustic speaker for the RASS measurement can be seen in the vertical profiles of the received echo power. Samples of the RASS echo power profiles are shown in Fig. 5, along with profiles of radiosonde wind speed and horizontal displacement of the sound beam center for RASS from that of the radio wave. The samples were selected from the days (Table 3) when surface winds were light $\left(<2 \mathrm{~m} \mathrm{~s}^{-1}\right)$ except on 19 October (Fig. 5a). The 

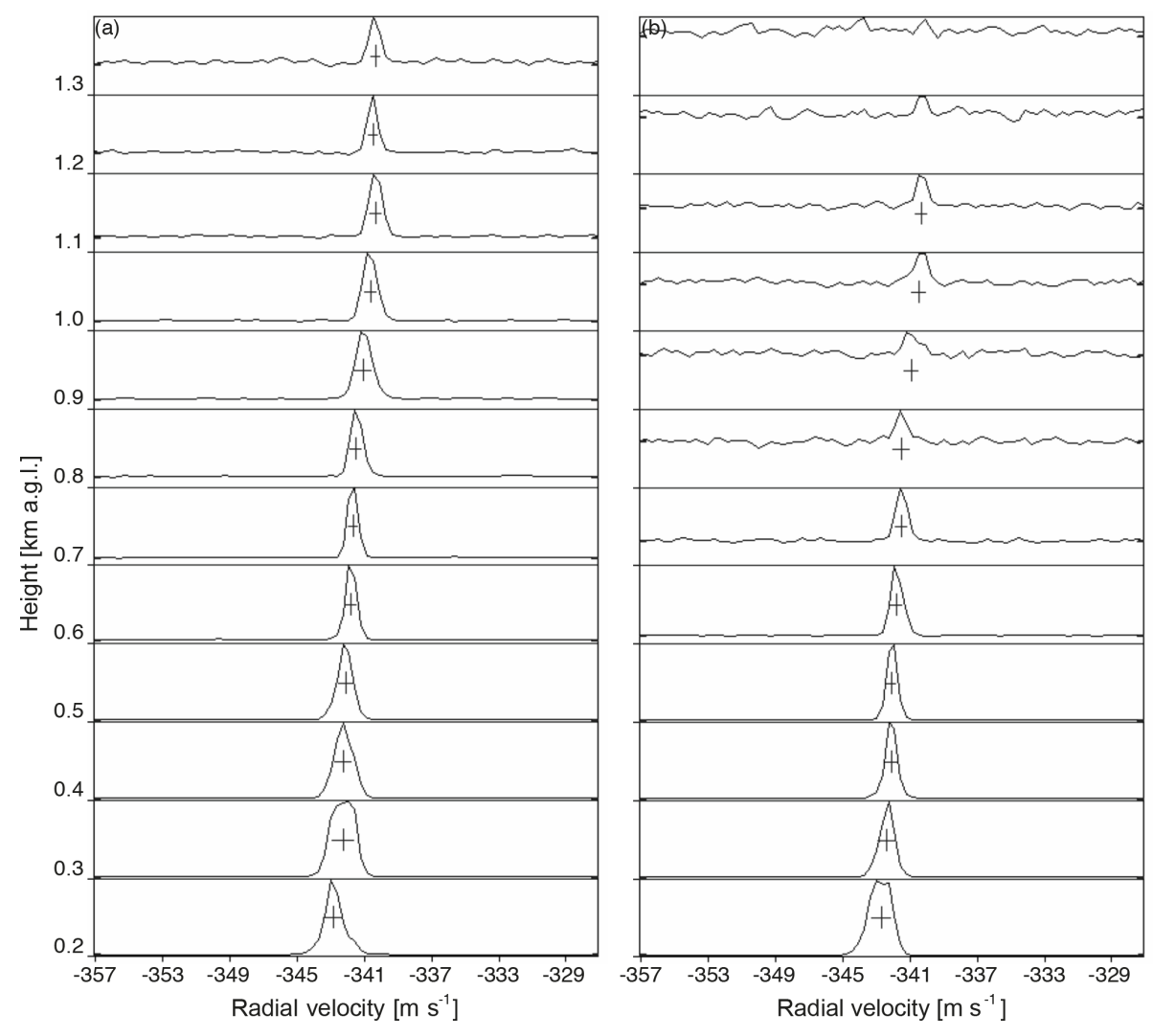

Figure 4. Doppler spectra from RASS observations measured with (a) acoustic speakers from 08:30 JST for 1 min and (b) the parametric speaker from 08:31 JST for 1 min on 19 October 2016. At each height, the first moment of the spectrum, indicated by the vertical bar, gives the vertical sound velocity, and the second moment, indicated by the horizontal bar, gives the spectral width.

displacement of the sound wave with horizontal wind was estimated by acoustic ray tracing based on radiosonde measurements. In this estimation, the sound speed was estimated using Eq. (1), assuming a stationary atmosphere, in which the virtual temperature was obtained from the radiosonde data, and the initial displacement of the PAA from the profiler antenna on the ground was set at $4 \mathrm{~m}$ (Fig. 1a). The RASS echo power shown here is a relative value, not absolute, because the profiler is not calibrated for received power.

The RASS echo power of both speaker systems decreased with altitude except for the first range gate. The reason for the decrease may include atmospheric attenuation of the acoustic signal and displacement of the acoustic wave from the radar antenna by the wind (Lataitis, 1992), as shown by the displacement profiles (Fig. 5). The echo power with the acoustic speakers was almost always larger than that of the PAA (Fig. 5a-d). This could be explained by the acoustic speaker's larger peak power than that of the PAA (Fig. 2), and the integrated peak power of the acoustic system, which comprises four speaker units (Fig. 1), could be much larger. The echo power with the PAA was slightly larger than that of the acoustic speakers at the first gate in Fig. 5a. This could be because the sound from the PAA was advected above the an- tenna as shown by no displacement at that height in the figure, suggesting that acoustic ray tracing was reliable. The estimation of RASS echo power (e.g., Adachi et al., 1993) was beyond the scope of this study. However, the echo power with both speaker systems in light-wind conditions (Fig. 5b-d) decreased almost linearly (in decibel space) with altitude above the first gate, and the difference in the gradient between the two systems was relatively small (less than $15 \%$ on average), although this small difference may also be attributable to the wind. From the facts mentioned above, we concluded that the secondary audible waves formed by the PAA can propagate over a long distance along the radio wave while satisfying the Bragg condition and are applicable to the RASS measurements as the sound wave generated by the acoustic speaker.

Since the PAA was shown to be applicable to the RASS measurements, we next explored the reliability of the PAARASS measurements by comparing with radiosonde observations. It is noteworthy, however, that in Fig. 5a, the echo power with the PAA decreased with altitude more sharply than that associated with the acoustic speaker at altitudes between 300 and $700 \mathrm{~m}$ a.g.l., where relatively high winds were observed, despite the fact that the PAA-RASS echo reached 

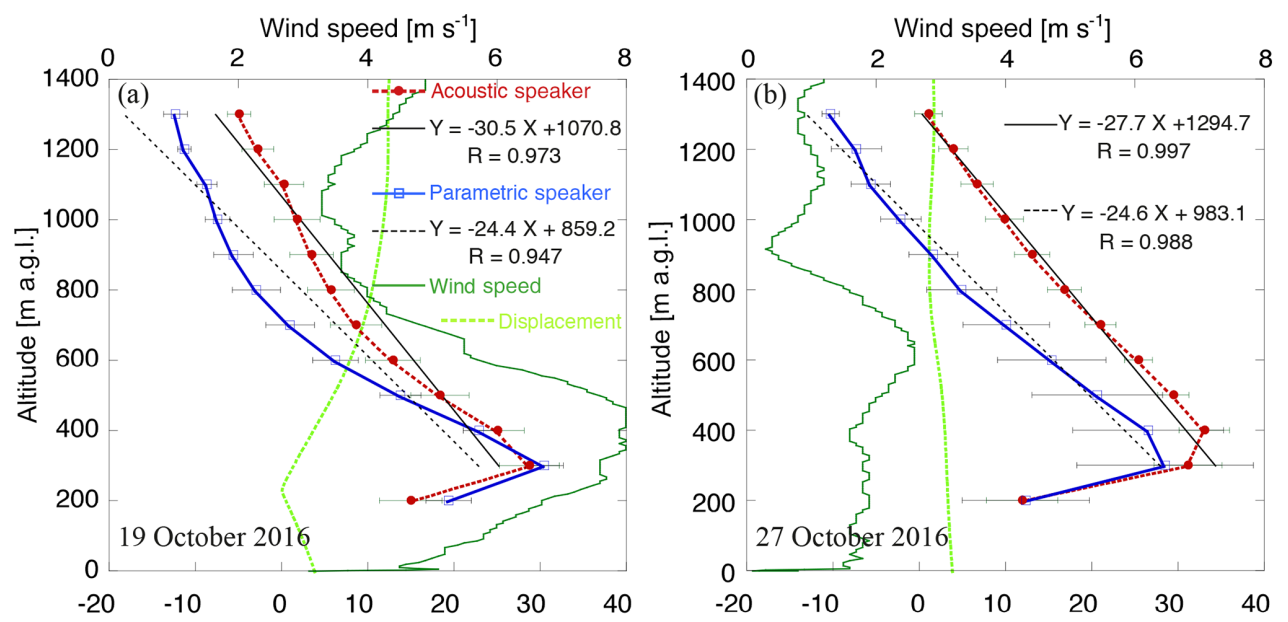

Received power $[\mathrm{dB}] /$ horizontal displacement $[\mathrm{m}]$
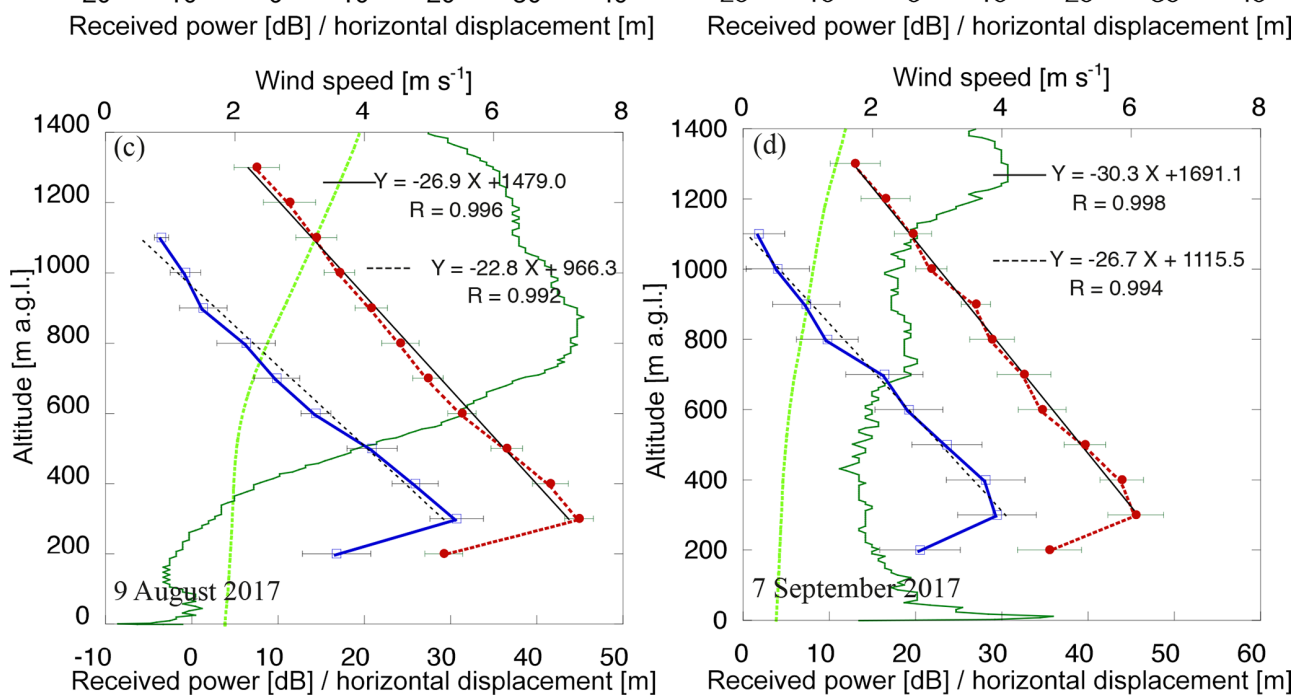

Figure 5. Profiles of received mean RASS echo power, horizontal displacement of the parametric speaker sound from radio wave, and wind speed on (a) 19 October 2016, (b) 27 October 2016, (c) 9 August 2017, and (d) 7 September 2017, derived with the acoustic speakers (red), the parametric speaker (blue), and radiosonde (green). The error bars represent $2 \sigma$. The black lines indicate linear regressions for the received power data (except for the first range) as shown in the upper-right legend with correlation coefficients.

the highest range gate (1300 $\mathrm{m}$ a.g.l.) similar to the acoustic speaker RASS. This suggests that the PAA has enough peak power to reach the highest range gate but is more susceptible to high winds than the acoustic speakers. Thus, the effect of wind on the PAA-RASS measurements is discussed later in this paper.

\subsection{Comparisons with radiosonde}

Profiles of virtual temperature $\left(T_{\mathrm{v}}\right)$ derived from radiosonde, the PAA-RASS, and the acoustic speaker RASS observations are shown in Fig. 6 along with the corresponding statistics for the data and the received power for both the PAA and acoustic speakers. The RASS data were averaged over approximately an hour. The radiosonde data were smoothed by $100 \mathrm{~m}$ running mean to match the RASS observations. The running mean may also play a role in mitigating the effect of the temperature fluctuation due to turbulence on the radiosonde measurements. The $T_{\mathrm{v}}$ derived from the radiosondes was in good agreement with the RASS measurements derived from both speaker systems, lying within the error bar of most of the range gates. In addition, $T_{\mathrm{v}}$ values derived with both speaker systems were close to each other. However, bias and standard deviation tended to be large at inversion layers and at the first gate (e.g., Fig. 6a, b, and c), the latter of which may correspond to the smaller received power at that gate. This could be attributable to the fact that the first gate is too close to the antenna. In fact, Lataiti (1992) suggested that factors including the recovery of the receiver and incomplete overlapping of the electromagnetic and acoustic beams due to the special separation between the antenna and speaker systems can lead to a significant gradient in the receiving power at this gate. In addition, a range error (e.g., Angevine and Ecklund, 1994; Görsdorf and Lehmann, 2000; 
Johnston et al., 2002) caused by the height variation in the backscatter intensity may also contribute to the smaller received power. It is also noteworthy that most of the highest range gates correspond to a received RASS echo power of about $-10 \mathrm{~dB}$ for both speaker systems in Figs. 5 and 6, suggesting that the received power is one of the factors determining the height coverage, although factors that determine the received power including the sound attenuation may be different for each system.

Scatter diagrams comparing radiosonde virtual temperature with that from RASS for all experiments are shown in Fig. 7 along with statistics. The first range gate data of the RASS measurements were not considered because they are less reliable. This figure shows that both the PAA and acoustic speaker RASS measurements of virtual temperature were generally in good agreement with those derived from radiosonde measurements, as expected. The linear regressions for both speaker systems were close to the 1-to-1 relation, and correlation coefficients were close to unity. In addition, the systematic error was less than $0.1{ }^{\circ} \mathrm{C}$ and the standard deviation was $0.4{ }^{\circ} \mathrm{C}$ for both systems, suggesting that both systems are reliable for RASS measurements.

\section{Discussions}

As reported above, we found many instances in which the PAA speaker system exhibited comparable performance with the acoustic speakers with respect to the RASS measurements in observing profiles of the Doppler spectrum and the virtual temperature, as shown in the statistics for the comparisons both with radiosonde and with the acoustic speaker RASS. Indeed, the bias and standard deviation for each speaker system RASS with respect to radiosonde are in good agreement with results reported in previous studies (e.g., Görsdorf and Lehmann, 2000), despite no correction for vertical velocity being performed. This could be partly because the experiments were conducted on fine days with light wind and because of the application of a relatively long averaging time. In addition, removing the first gate data from the statistics may also have contributed to the good results.

Although applying a long averaging time could mitigate the effect of vertical airflow on bias (e.g., Moran and Strauch, 1994), it may degrade the statistics when the virtual temperature profile evolves within the duration of the RASS measurement. On the other hand, the statistics also indicated that the data number associated with the PAA was smaller than that of the acoustic speakers (e.g., Fig. 6), implying that the mean height coverage with the former was lower than that of the latter presumably because of wind in addition to the low peak power mentioned previously (Fig. 2). Thus, we independently focus our attention on both the effects of the time evolution of the temperature profile on the statistics and of wind on the height coverage of the RASS measurement in the following sections.

\subsection{Effect of rapid time evolution of temperature profile}

In the comparisons, the RASS data were averaged for a relatively long time to minimize the effects of both vertical velocity and the spatial difference between the radiosonde and the profiler with RASS. However, the temperature profiles derived from radiosonde observations may not be well suited for use as standard reference data if the temperature profile evolved rapidly within the hour-long RASS observation duration. In the experiments, since the operational radiosondes were launched in the morning on fine days with light winds, an inversion layer was frequently observed (Fig. 6). In fact, 12 inversions including multiple inversion layers (e.g., Fig. 6b) were observed in 8 of the 16 experiments. Inversion layers can evolve in a relatively short time due to surface heating and cooling and/or the development of the boundary layer in the morning. Indeed, the surface virtual temperature increased by $2.3^{\circ} \mathrm{C}$ on average with a standard deviation of $1.0^{\circ} \mathrm{C}$ within an hour for the experiments shown in Fig. 6 . Thus, the temperature profile measured with the radiosonde can differ from the mean temperature profile obtained from RASS even though both measurements represented an actual profile, which may result in degrading the statistics for the RASS evaluation.

A sample of the temperature profile observing an inversion layer is shown in Fig. 8. This observation was made more than $3 \mathrm{~h}$ after sunrise (05:15 JST) on that day. The $T_{\mathrm{v}}$ profiles with error bars were the mean RASS measurements averaged over an hour from acoustic (red) and PAA (blue) speakers. Both RASS profiles represented the radiosonde profile to some extent but did not follow the profile well, especially around the inversion layer. The large standard deviations indicated by long error bars may reflect the time evolution of the temperature profile in addition to the measurement precision of RASS. By contrast, the 1 min raw RASS data recorded around the radiosonde launch time represented the inversion layer better than the mean RASS measurements at some points, although there were still some discrepancies, which may have been due to the locality of the inversion layer, the effects of vertical air motion or turbulence, or the time difference between RASS and radiosonde in addition to the accuracy and precision of the RASS measurements. The discrepancy above the inversion layer may be caused by the locality of the temperature because the MRI observation field covered by vegetation (Adachi et al., 2005) ends about $500 \mathrm{~m}$ from the profiler, which corresponds to the horizontal displacement at that height. On the other hand, the discrepancies in and below the inversion could be mitigated by considering the effect of the vertical airflow and/or applying a range correction. In terms of the time difference, it is noteworthy that the radiosonde measurement is not a snapshot but sequential; it took more than $2 \mathrm{~min}$ for the radiosonde to ascend to an altitude of $800 \mathrm{~m}$ a.g.l., and the temperature profile may evolve even during this time. Thus, a comparison with mea- 

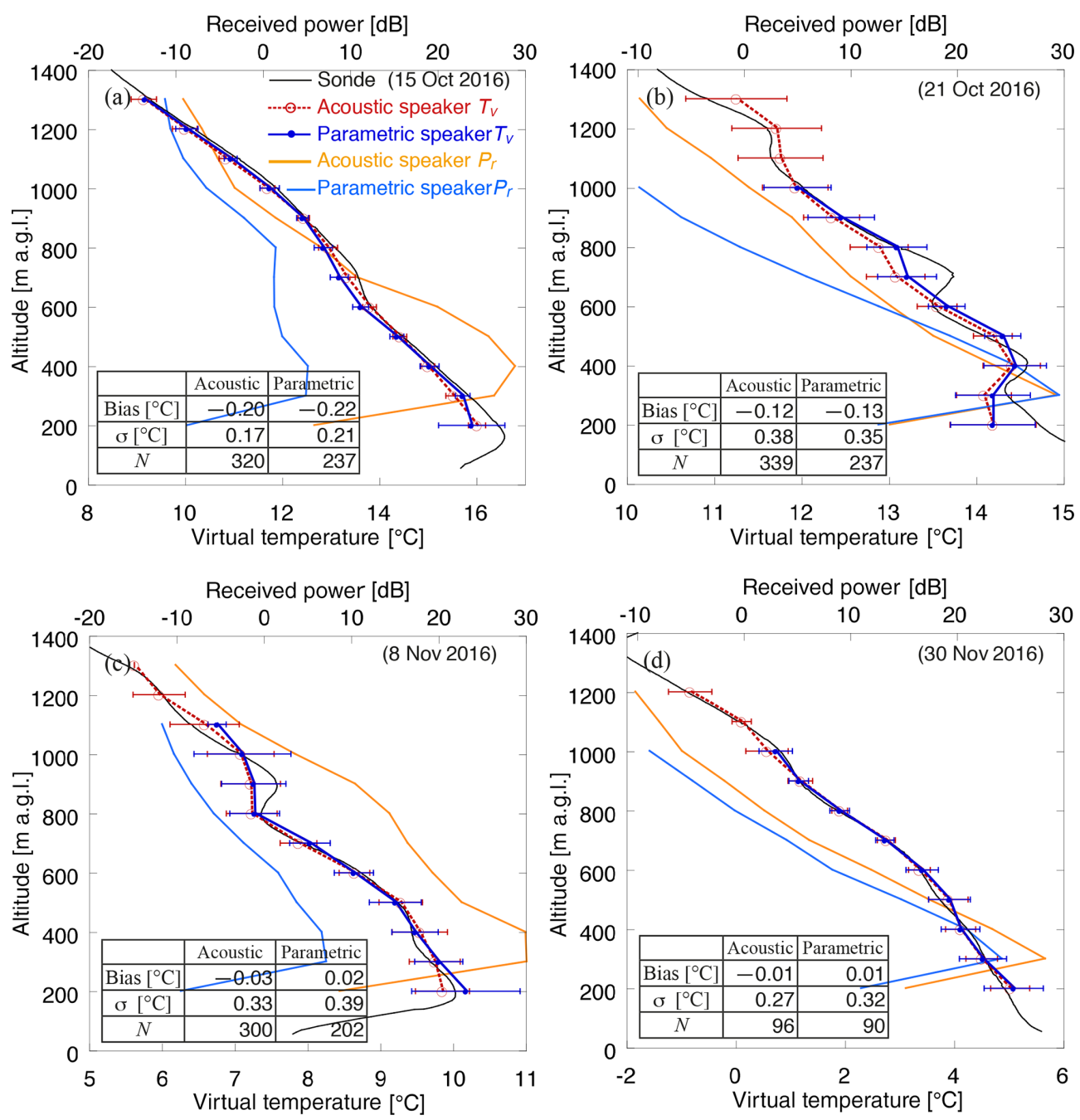

Figure 6. Profiles of virtual temperature $\left(T_{\mathrm{V}}\right)$ and received power $\left(P_{\mathrm{r}}\right)$ from 08:30 JST on (a) 15 October, (b) 21 October, (c) 8 November, and (d) 30 November 2016 derived from a radiosonde (black), RASS with acoustic speakers (red and orange), and the parametric speaker (blue). The radiosonde data were smoothed by $100 \mathrm{~m}$ running means to match with the vertical resolution of the RASS. The error bars represent $2 \sigma$ in the RASS hourly observations. The mean, standard deviation, and number of samples of temperature difference are summarized in a table in each panel.

surements that have both small spatial difference and high time resolution is needed to evaluate the PAA-RASS measurement.

\subsection{Comparison with acoustic speaker RASS}

To suppress the effects of the spatial and time difference between the two platforms on the evaluation, we next compared the temperatures derived from the PAA-RASS with those from the acoustic speaker RASS. Of course, this comparison does not provide an absolute but relative evaluation of the PAA-RASS measurement. This issue should be kept in mind in examining the intercomparisons presented in this section. In the intercomparison, the requirements for highquality upper-air reference data (bias $\leq 0.1, \sigma \leq 0.2 \mathrm{~K}$ ) proposed by WMO (2007) for the GRUAN were used as criteria for the evaluation, although they are not for virtual temperature but for real temperature.

A normalized frequency diagram and scatterplot of virtual temperature obtained by the acoustic speaker RASS versus the PAA-RASS are shown in Fig. 9. The 1 min raw data obtained alternately are presented in Fig. 9a, whereas the data averaged for about an hour are plotted in Fig. 9b. Figure 9a shows that the PAA-RASS measurements of virtual temperature were generally in good agreement with those of the acoustic speaker RASS despite disregarding the time difference in the two systems. The linear regression line was close to the 1-to-1 relation, and the correlation coefficient was close to unity. Moreover, the mean bias and standard deviation of the difference between the two speaker systems were less than $0.1{ }^{\circ} \mathrm{C}$ and close to $0.4{ }^{\circ} \mathrm{C}$, respectively, which 


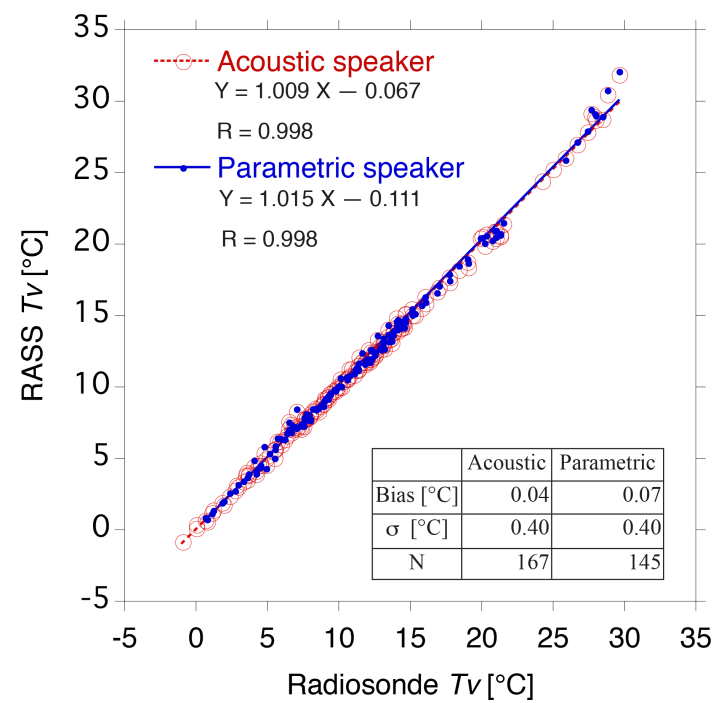

Figure 7. Scatterplots of virtual temperature of the RASS vs. the radiosonde measurements at all heights except for the first range. The data derived from the RASS with the acoustic speakers (the parametric speaker) are plotted as open (closed) circles. The radiosonde data were smoothed by $100 \mathrm{~m}$ running means to match with the vertical resolution of RASS. The lines represent linear regressions for each data set as shown in an upper legend along with the correlation coefficients. The mean, standard deviation, and number of samples of temperature difference are summarized in the bottom table.

are comparable with those obtained by the comparison with radiosonde measurements (Fig. 7) despite the higher time resolution. Since the spatial difference was negligible and the time difference was quite small, the reason for this discrepancy could include temperature fluctuation due to turbulence. Indeed, the mean (max and $\min$ ) increase in the virtual temperature at the surface for all the experiments was $0.2 \pm 0.5^{\circ} \mathrm{C}\left(1.4^{\circ} \mathrm{C},-1.3{ }^{\circ} \mathrm{C}\right)$ in $10 \mathrm{~min}$, which suggests that temperature fluctuation aloft was occurring.

A scatter diagram comparing the mean acoustic speaker RASS measurements with those from the parametric speaker RASS is shown in Fig. 9b. The data were averaged over about an hour to minimize the effect of temporal fluctuation of temperature and improve the statistics. Indeed, the linear regression was close to the 1-to- 1 relation, and the correlation coefficient was closer to unity. In addition, both the bias $\left(0.06^{\circ} \mathrm{C}\right)$ and standard deviation $\left(0.16^{\circ} \mathrm{C}\right)$ improved and satisfied the WMO requirements.

From the evaluations mentioned above, we conclude that the accuracy and precision of the parametric speaker RASS are comparable with those of the acoustic speaker RASS for measuring the vertical profile of virtual temperature. The reliability of the parametric speaker RASS could be improved by applying the time average over the appropriate period, advanced quality control, and/or corrections for both range and vertical airflow as long as the effect of the ground clutter is negligibly small.

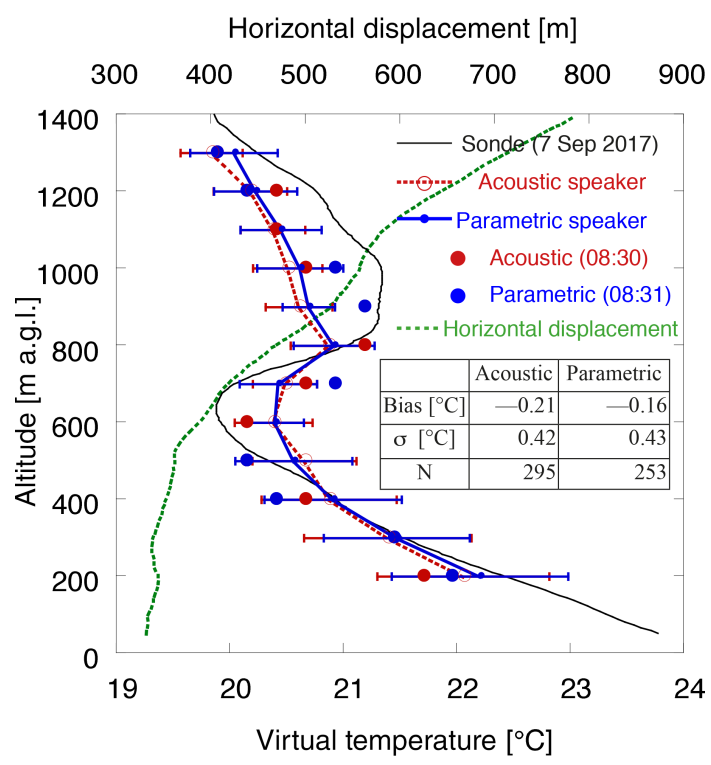

Figure 8. Profiles of the virtual temperature $\left(T_{\mathrm{V}}\right)$ from 08:30 JST on 7 September 2017, derived from a radiosonde (black), RASS with acoustic speakers (red), with the parameter speaker (blue), and horizontal displacement of the radiosonde from the profiler (green). The radiosonde data were smoothed by $100 \mathrm{~m}$ running means to match with the vertical resolution of RASS. The error bars represent $2 \sigma$ in the RASS observations averaged over $60 \mathrm{~min}$, and closed circles represent 1 min raw data from the time indicated. The mean, standard deviation, and number of samples of temperature difference of RASS from radiosondes are summarized in the table.

\subsection{Effect of horizontal wind on the height coverage of the RASS measurement}

The reliability of the parametric speaker RASS measurement was shown to be equivalent to the acoustic speaker RASS. However, we found many instances in which the former tended to have less height coverage than the latter (Figs. 4, 5 , and 6), which is also reflected by the fewer number of data in the statistics (Figs. 6, 7, and 8). Although the parametric speaker system exhibited less peak power than the acoustic speaker system, the weak power cannot be the only reason for the lower height coverage because the results show that the former can observe up to the highest range gate as the latter as long as the received power is more than about $-10 \mathrm{~dB}$ (e.g., Figs. 5a, b, 6a, and 8). On the other hand, the results also suggest that the reason may include the effect of wind aloft (e.g., Fig. 5a). Because the acoustic beam generated by the parametric speaker is narrow, it could be susceptible to the horizontal airflow, which displaces the acoustic wave from the radar antenna as shown in Fig. 5. Thus, the effect of horizontal wind on the height coverage of the parametric speaker RASS measurement was evaluated by comparing it with the radiosonde wind data.

A scatter diagram comparing the mean RASS height coverage and horizontal displacement of the center of the sound 


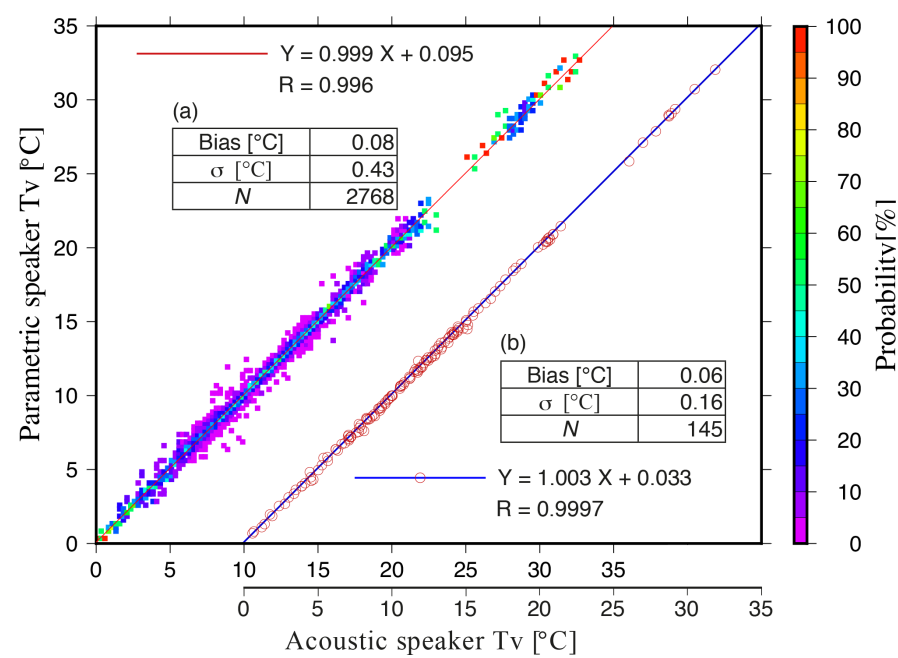

Figure 9. Comparisons of the parametric speaker vs. the acoustic speakers in measuring virtual temperature at all heights (except for the first gate) shown by (a) a normalized frequency diagram (color scale) and (b) a scatterplot. The data obtained from each speaker system every $1 \mathrm{~min}$ alternately were used in (a), whereas the hourlymean data were plotted in (b). The mean $T_{\mathrm{V}}$ derived with the acoustic speakers is shifted $10^{\circ} \mathrm{C}$ for ease of viewing in (b). The lines represent linear regressions for each data set, shown in the upperleft and lower-right legends along with correlation coefficients, respectively. The mean, standard deviation, and number of samples of temperature difference are summarized in each table.

for RASS from that of the radio wave at $1200 \mathrm{ma.g.l}$. is shown in Fig. 10, as well as the mean wind speed aloft. The horizontal displacement was estimated by acoustic ray tracing. In the estimation, the initial displacement of the acoustic speaker system from the profiler antenna on the ground was set at $0 \mathrm{~m}$ because the antenna is surrounded by the four acoustic speakers, whereas that of the PAA was set at $4 \mathrm{~m}$ (Fig. 1a). The wind speed aloft is the mean wind from 20 to $1200 \mathrm{~m}$ a.g.l. (Table 3), which is the highest mean coverage of the parametric speaker RASS measurements in calm wind conditions $\left(<2 \mathrm{~m} \mathrm{~s}^{-1}\right)$ as shown in the figure. The data measured on 30 November 2016 are not considered in the analysis because the RASS measurement was made more than 40 min later than the radiosonde observation (Table 3). Note that the mean RASS height coverage shown in the figure is different from the height coverage of the mean virtual temperature profile in Fig. 6 because the latter reflects the maximum height coverage within the observed profiles after quality control in the duration of the RASS measurement. The long error bars may reflect the large time evolution of the RASS height coverage, which may also be related to the evolution of the wind in the duration.

The parametric speaker RASS measurements tended to reach lower altitude than the acoustic speaker RASS, even when the horizontal displacement was less than $10 \mathrm{~m}$ (corresponding to a wind speed of around $4 \mathrm{~m} \mathrm{~s}^{-1}$ ). The reason

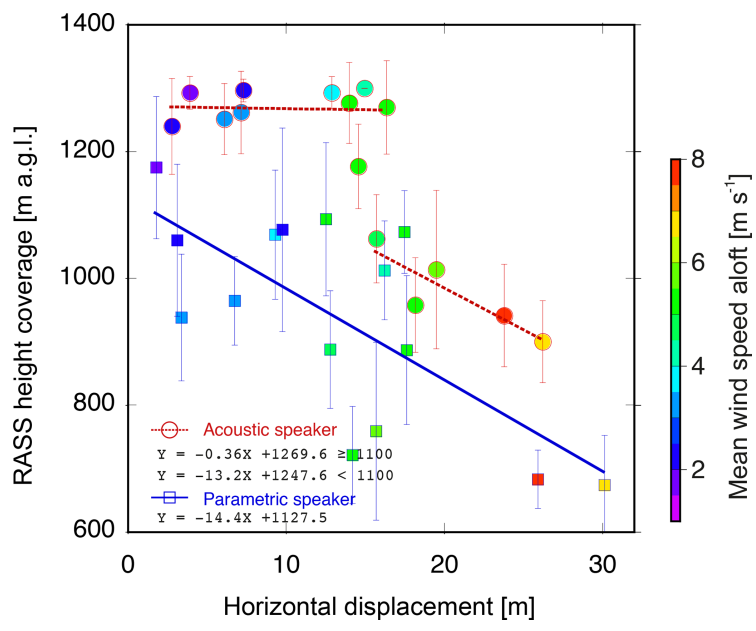

Figure 10. Scatterplots of mean height coverage of RASS measurement vs. horizontal displacement of the beam center of the sound for RASS from that of the radio wave at $1200 \mathrm{~m}$ a.g.l. derived from radiosonde observations. Closed circles (squares) denote the observed mean RASS height coverage by acoustic speakers (parametric speaker) with standard deviations indicated by error bars. The color scale represents the mean wind speed aloft (20$1200 \mathrm{~m}$ a.g.1.). Thick lines represent linear regressions for each data set, where the acoustic data are divided by a height threshold of $1100 \mathrm{~m}$ a.g.l. The highest range gate sampled for the RASS measurement is $1300 \mathrm{~m}$ a.g.l.

for the lower coverage under small displacement (light wind) conditions may include the parametric speaker's lower peak power than that of the acoustic speaker system. The height coverage decreased with the displacement and/or wind speed for the parametric speaker RASS, as indicated by the linear regression analysis. In contrast, when the displacement is less than $16 \mathrm{~m}$ (corresponding to a wind speed of around $6 \mathrm{~m} \mathrm{~s}^{-1}$ ), most of the acoustic speaker RASS measurements achieved a height coverage of around $1300 \mathrm{~m}$ a.g.l., which was the highest range gate for the RASS measurement (Table 1). This suggests that the acoustic speaker RASS keeps on observing at a high altitude even in relatively high wind conditions, as also indicated by the short error bars.

It is noteworthy, however, that the height coverage of RASS with acoustic speakers drops sharply to $1000 \mathrm{~m}$ a.g.l. at a horizontal displacement of 15-16 $\mathrm{m}$ and exhibits a tendency to decrease with the displacement afterward similar to the parametric speaker RASS. By contrast, the height coverage of the parametric speaker tends to decrease monotonically with the displacement at almost all ranges. These results suggest that the parametric speaker RASS is more sensitive to wind because of the narrow beam, whereas the acoustic speaker RASS is surprisingly robust. Since the four acoustic speakers were not adjusted in phase, this robustness could be explained by the higher aggregate sound power than that shown in Fig. 2 and possible location of sound wave above the antenna in spite of relatively high winds. 
To compensate for the lower wind tolerance, two additional experiments were performed, in which the acoustic beam was broadened and steered. The parametric speaker system employed for the RASS experiments was equipped with FPGA that controlled the beam pattern of the sound, including beam width and direction. We broadened the beam width from 5 to $12^{\circ}$ (Fig. 2) when the parametric RASS echo was observed up to an altitude of $1200 \mathrm{~m}$ a.g.l. However, this experiment resulted in a decrease in the height coverage to $500 \mathrm{~m}$ a.g.l. The height coverage decrease could have been due to the decrease in the peak power associated with beam broadening. In fact, the measured peak power was decreased by $15 \mathrm{~dB}$ in our system by broadening the beam (Fig. 2). Therefore, by using this technique, a parametric speaker with more peak power was needed in our case to acquire equivalent height coverage with the acoustic speaker system, which may result in increasing both the size and cost of the system.

On the other hand, the peak power does not decrease significantly with the zenith angle of the beam as long as the angle is small. The SPL pattern at multiple zenith angles measured in the field is shown in Fig. 11. The peak power was decreased by about $7.5 \mathrm{~dB}$ by reducing the power supply to the PAA amplifier, which decreased not only the audible sound but also the ultrasound levels for practical reasons (noisy) and measurement safety. The results indicated that the peak power decreased by only $3.8 \mathrm{~dB}$ when the beam was steered to a zenith angle of $10^{\circ}$, which corresponds to a horizontal wind speed of $60 \mathrm{~m} \mathrm{~s}^{-1}$. The sound wave might be displaced by the horizontal wind but advected to above the antenna if the wave is generated windward with an appropriate zenith angle. Thus, we conducted another experiment with the acoustic beam zenith angle of $2^{\circ}$ windward on a day when a mean wind speed of about $12 \mathrm{~m} \mathrm{~s}^{-1}$ between 200 and $1200 \mathrm{ma.g.1}$. was observed with the wind profiler. Unfortunately, no RASS echo was observed, which may be partly because the sound wave did not propagate vertically to the ground, and the advected sound wave front above the antenna was not normal to the propagation direction of the radio wave. Additionally, the acoustic wave front may have been distorted by wind shear. In that case, the radio wave might have been steered to the direction normal to the sound wave front by considering the advection and distortion of the sound wave front from the wind profiler measurements.

\subsection{Health effects of ultrasound exposure}

Since the ultrasonic SPL generated by the PAA is extremely high $(>200 \mathrm{~dB})$, the health effects of ultrasound exposure in the area close to the PAA should be considered. In studies involving small animals (WHO, 1982), mild biological changes have been reported during prolonged exposure to airborne ultrasound with levels in the range of 95-130 dB at frequencies ranging from 10 to $54 \mathrm{kHz}$, which become more severe with increasing SPL. Thus, the PAA should not be installed on or under the ground level, as it can be easily ac-

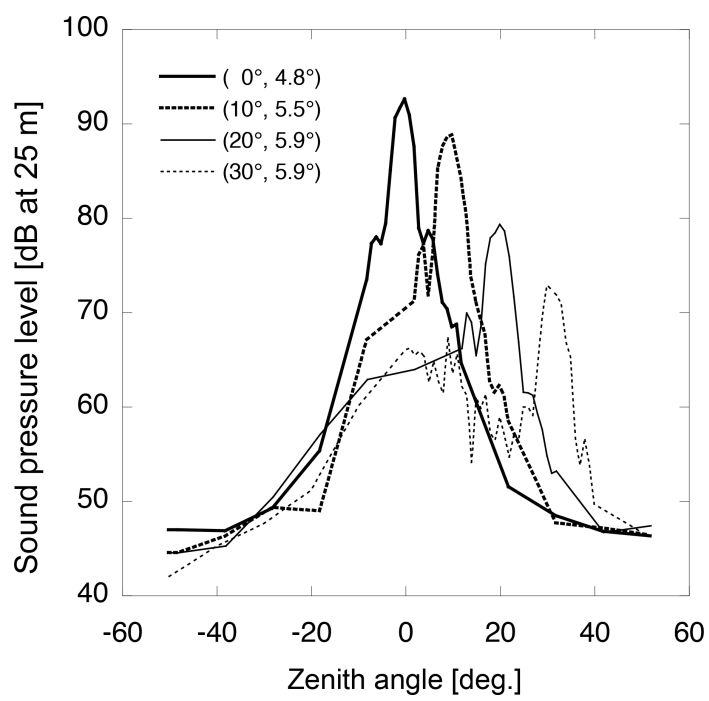

Figure 11. Audible sound pressure pattern of the parametric speaker at a frequency of $3 \mathrm{kHz}$ measured at multiple zenith angles, shown in the upper legend with the beam width observed. Note that the peak SPL was decreased by about $7.5 \mathrm{~dB}$ for safety. The SPL was measured with a sound level meter (Rion NL-42).

cessed by animals. Because the PAA for RASS emits sound vertically, animals aloft, including birds and/or insects, can be exposed to the sound beam. However, those animals are capable of avoiding the risk quite easily because they can perceive the audible sound from the PAA, and the beam width is very narrow. In fact, no animals, including bugs and/or birds, have died so far on the PAA after more than $100 \mathrm{~h}$ of operation.

On the other hand, no adverse physiological or auditory effects appear to occur in humans exposed to sound pressure levels up to about $120 \mathrm{~dB}$ (WHO, 1982; Health Canada, 1991). At $140 \mathrm{~dB}$, mild heating may be felt in the skin clefts. With increasing sound pressure levels, the human body becomes warmer until death from hyperthermia. This has been estimated to occur at levels greater than $180 \mathrm{~dB}$. This lethal threshold value corresponds to a distance of less than $17 \mathrm{~m}$ from the PAA, with an ultrasonic SPL of $200 \mathrm{~dB}$, assuming an atmospheric attenuation of $1.2 \mathrm{~dB} \mathrm{~m}^{-1}$ (Fig. 3). To avoid ultrasound exposure, we installed the PAA on top of a shed with a height of $2 \mathrm{~m}$ so that the speaker will not be accessed by anyone. Moreover, rotational warning lights were installed on the wall of the shed (Fig. 1d) to alert people to the emission of ultrasound of more than $50 \mathrm{~dB}$ (yellow) and/or $100 \mathrm{~dB}$ (red).

\section{Conclusions}

We investigated the applicability of parametric speakers to RASS for measuring the vertical profile of virtual temperature by comparing the data with those obtained from both ra- 
diosonde and the acoustic speaker RASS. In the experiments, the operations of the two speaker systems were swapped every minute alternately for the comparison. A detailed analysis of the profiles of both the acoustic attenuation and the Doppler spectrum suggest that although the primary ultrasound generated by the parametric speaker may be dissipated greatly as altitude increases, the secondary audible waves generated from the bifrequency ultrasound can propagate long distances while satisfying the Bragg condition.

We have also compared parametric speakers with both radiosonde and acoustic speakers to estimate the reliability of RASS in measuring the virtual temperature $\left(T_{\mathrm{V}}\right)$. The results indicated that $T_{\mathrm{V}}$ measured with parametric speaker RASS has comparable reliability with the acoustic speaker RASS measurements; the bias and standard deviation $\left(0.1^{\circ} \mathrm{C}, 0.4^{\circ} \mathrm{C}\right)$ for the parametric speaker were close to those for the acoustic speaker $\left(0.0^{\circ} \mathrm{C}, 0.4^{\circ} \mathrm{C}\right)$ with respect to radiosonde, which was consistent with the results reported in previous studies, although the conditions in those studies, including the corrections for the vertical wind and/or range, were different from ours. We also found that not only the spatial difference between the two platforms but also both the evolution of the temperature profile during the RASS measurement and temperature fluctuation due to turbulence could contribute to deterioration of the statistics. To mitigate these effects, a comparison of virtual temperature obtained from the two speaker systems was also performed. The results indicated that the bias and standard deviation $\left(0.1{ }^{\circ} \mathrm{C}, 0.2^{\circ} \mathrm{C}\right)$ of the parametric speaker RASS were quite small and satisfied the requirements for high-quality upper-air reference data proposed by the WMO (2007). Taken together, we conclude that parametric speaker RASS has comparable accuracy and precision with acoustic speaker RASS with respect to the measurement of the virtual temperature profile.

We examined the height coverage of RASS and found that the parametric speaker deployed in the experiments tended to have less coverage than the acoustic speakers, which may be a result of the parametric speaker having high directivity, and the generated sound was more susceptible to the displacement from the radar antenna by horizontal wind than the sound wave by the acoustic speakers. Thus, we broadened the beam width of the parametric speaker, which resulted in degrading height coverage because this operation deteriorates the peak power of the audible sound. The sound wave was then steered windward with the default beam width $\left(\sim 5^{\circ}\right)$ so that the advected sound was located above the antenna. However, no echo was observed, presumably because the sound wave front advected to above the antenna was not normal to the propagation direction of the radio wave in the experiments. In addition, the sound wave front may have been distorted by wind shear. This issue might be solved by using wind profilers that are capable of steering the radio wave (e.g., Adachi and Kobayashi, 2001; Law et al., 2002; Palmer et al., 2005) to the direction normal to the sound wave front as Masuda (1988) proved with the middle and upper atmosphere (MU) radar (Fukao et al., 1985).

The results of this study including the statistics do not necessarily apply to all locations, altitudes, and seasons; in particular, we note that the comparisons in this case study were made in the morning on fine days with light wind when the effects of horizontal and vertical wind would be less expected. Nevertheless, we confirm that a parametric speaker is applicable to RASS measurement with a reliability comparable with acoustic speakers. Although it is sensitive to horizontal wind, this type of speaker could be installed to wind profilers located in urban areas for continuous observations for operation (e.g., Ishihara et al., 2006) to improve weather forecast because it has high directivity and no horizontal sound wave leaks to annoy nearby residents.

Data availability. All the observation data used for the present study are available from the authors upon request. 


\section{Appendix A: Calculation of the atmospheric attenuation}

The method of estimating attenuation coefficient for atmospheric absorption from temperature, humidity, and pressure is summarized here based on ISO 9613-1 (ISO, 1993). The attenuation coefficient $\alpha\left(\mathrm{dB} \mathrm{m}^{-1}\right)$ is expressed by the sum of four terms in good approximation as

$\alpha=\alpha_{\mathrm{cl}}+\alpha_{\mathrm{rot}}+\alpha_{\mathrm{vib}, \mathrm{O}}+\alpha_{\mathrm{vib}, \mathrm{N}}$

where $\alpha_{\mathrm{cl}}$ represents the classical absorption caused by the transport processes, $\alpha_{\text {rot }}$ is the molecular absorption by rotational relaxation, and $\alpha_{\mathrm{vib}, \mathrm{O}}$ and $\alpha_{\mathrm{vib}, \mathrm{N}}$ indicate the molecular absorption caused by vibrational relaxation of oxygen and nitrogen, respectively. The molecular absorption by other compositions of the air including carbon dioxide is small and neglected in the calculation.

The first two terms of Eq. (A1) related to the classical and rotational absorption are given by their sum, $\alpha_{\mathrm{cr}}$ :

$\alpha_{\mathrm{cr}}=\alpha_{\mathrm{cl}}+\alpha_{\mathrm{rot}}=1.60 \times 10^{-10}\left(\frac{T}{T_{0}}\right)^{\frac{1}{2}}\left(\frac{P_{\mathrm{a}}}{P_{\mathrm{r}}}\right)^{-1} f^{2}$,

where $T(\mathrm{~K})$ is the atmospheric temperature, $T_{0}$ is the reference air temperature $(293.15 \mathrm{~K}), P_{\mathrm{a}}(\mathrm{hPa})$ is the atmospheric pressure, $P_{\mathrm{r}}(\mathrm{hPa})$ is the reference air pressure $(1013.25 \mathrm{hPa})$, and $f(\mathrm{~Hz})$ is the sound frequency.

The two vibrational relaxation terms in Eq. (A1) are given respectively by

$\alpha_{\mathrm{vib}, \mathrm{O}}=\left[(\alpha \lambda)_{\max , \mathrm{O}}\right] \times \frac{f}{c_{\mathrm{s}}} \times\left\{2\left(\frac{f}{f_{\mathrm{rO}}}\right)\left[1+\left(\frac{f}{f_{\mathrm{rO}}}\right)^{2}\right]^{-1}\right\}$

and

$\alpha_{\mathrm{vib}, \mathrm{N}}=\left[(\alpha \lambda)_{\max , \mathrm{N}}\right] \times \frac{f}{c_{\mathrm{s}}} \times\left\{2\left(\frac{f}{f_{\mathrm{rN}}}\right)\left[1+\left(\frac{f}{f_{\mathrm{rN}}}\right)^{2}\right]^{-1}\right\}$,

where subscripts $\mathrm{O}$ and $\mathrm{N}$ represent oxygen and nitrogen, respectively, $\left[(\alpha \lambda)_{\max }\right]\left(\mathrm{dB} \mathrm{m}^{-1}\right)$ represents the maximum attenuation by a vibrational relaxation over the distance of a wavelength, $\lambda(\mathrm{m}), c_{\mathrm{S}}\left(\mathrm{m} \mathrm{s}^{-1}\right)$ is the sound speed, and $f_{\mathrm{r}}(\mathrm{Hz})$ is the relaxation frequency.

The maximum attenuation by a vibrational relaxation for oxygen and nitrogen are given respectively by

$\left[(\alpha \lambda)_{\max , \mathrm{O}}\right]=\left(\frac{40 \pi}{35}\right)\left(\log _{10} e\right) X_{\mathrm{O}}\left(\frac{\theta_{\mathrm{O}}}{T}\right)^{2} \exp \left(-\frac{\theta_{\mathrm{O}}}{T}\right)$

and

$\left[(\alpha \lambda)_{\max , \mathrm{N}}\right]=\left(\frac{40 \pi}{35}\right)\left(\log _{10} e\right) X_{\mathrm{N}}\left(\frac{\theta_{\mathrm{N}}}{T}\right)^{2} \exp \left(-\frac{\theta_{\mathrm{N}}}{T}\right)$,

where $X_{\mathrm{O}}(=0.209476)$ and $X_{\mathrm{N}}(=0.78084)$ represent the standard molar concentrations of dry air, and $\theta_{\mathrm{O}}$
$(=2239.1 \mathrm{~K})$ and $\theta_{\mathrm{N}}(=3352.0 \mathrm{~K})$ are the characteristic vibrational temperature for oxygen and nitrogen, respectively.

The sound speed $c_{\mathrm{s}}$ in Eqs. (A3) and (A4) at a molecular concentration of water vapor of $h(\%)$ is given by

$$
\begin{aligned}
c_{\mathrm{S}} & =c_{\mathrm{a}} \times \sqrt{1-\frac{h}{100}\left(\frac{\gamma_{\mathrm{w}}}{\gamma_{\mathrm{a}}}-\varepsilon\right)} \\
& =c_{0} \times \sqrt{\frac{T}{T_{0}}} \times \sqrt{1-\frac{h}{100}\left(\frac{\gamma_{w}}{\gamma_{\mathrm{a}}}-\varepsilon\right)},
\end{aligned}
$$

where $C_{\mathrm{a}}$ is the sound speed for dry air, $\gamma_{\mathrm{w}}(=1.33)$ and $\gamma_{\mathrm{a}}$ $(=1.40)$ are heat capacity ratio for water vapor and dry air, respectively, $\varepsilon(=0.662)$ is the ratio of the molecular weight of water vapor to the molecular weight of air, and $C_{0}$ is the sound speed for dry air at the reference air temperature, $T_{0}$. The value of $h$ is given from the relative humidity, $h_{\mathrm{r}}(\%)$ by

$h=h_{\mathrm{r}}\left(\frac{P_{\text {sat }}}{P_{\mathrm{r}}}\right) /\left(\frac{P_{\mathrm{a}}}{P_{\mathrm{r}}}\right)=h_{\mathrm{r}}\left(\frac{P_{\mathrm{sat}}}{P_{\mathrm{a}}}\right)$,

where $P_{\text {sat }}(\mathrm{hPa})$ is the saturation vapor pressure given by

$P_{\text {sat }}=P_{\mathrm{r}} \times 10\left(-6.8346 \times\left(\frac{T_{01}}{T}\right)^{1.261}+4.6151\right)$,

and $T_{01}(=273.16 \mathrm{~K})$ is the triple-point isotherm temperature. The sound speed in dry air $C_{\mathrm{a}}$ is given by

$c_{\mathrm{a}}=\sqrt{\frac{\gamma_{\mathrm{a}} R}{M_{\mathrm{d}}} T}$,

where $R\left(=8.314 \mathrm{~J} \mathrm{~mol}^{-1} \mathrm{~K}^{-1}\right)$ is the universal gas constant, and $M_{\mathrm{d}}\left(=2.896 \times 10^{-2} \mathrm{~kg} \mathrm{~mol}^{-1}\right)$ is the molecular weight for dry air. By substituting values of $R$ and $M_{\mathrm{d}}$ in Eq. (A10), we may derive

$c_{\mathrm{a}}=20.048 \sqrt{T}$,

and $C_{0}=343.25 \mathrm{~m} \mathrm{~s}^{-1}$ at a temperature of $T_{0}$. Note that Eq. (A11) corresponds to Eq. (1) in stationary atmosphere because air temperature $T$ is equal to virtual temperature $T_{\mathrm{v}}$ in dry air.

The relaxation frequency for $\mathrm{O}$ and $\mathrm{N}$ is given by

$f_{\mathrm{rO}}=\left(\frac{P_{\mathrm{a}}}{P_{\mathrm{r}}}\right)\left(24+4.04 \times 10^{4} h \frac{0.02+h}{0.331+h}\right)$

and

$$
\begin{aligned}
f_{\mathrm{rN}} & =\left(\frac{P_{\mathrm{a}}}{P_{\mathrm{r}}}\right)\left(\frac{T}{T_{0}}\right)^{-\frac{1}{2}} \\
& \times\left[9+280 h+\exp \left[-4170\left\{\left(\frac{T}{T_{0}}\right)^{-\frac{1}{3}}-1\right\}\right]\right],
\end{aligned}
$$

respectively. 
By substituting Eqs. (A2)-(A11) in Eq. (A1), we may derive

$$
\begin{aligned}
\alpha \approx & 8.686 f^{2}\left[\left\{1.84 \times 10^{-11}\left(\frac{P_{\mathrm{a}}}{P_{\mathrm{r}}}\right)^{-1}\left(\frac{T}{T_{0}}\right)^{\frac{1}{2}}\right\}\right. \\
+ & \left(\frac{T}{T_{0}}\right)^{-\frac{5}{2}} \times\left\{0.01275 \times \exp \left(\frac{-2239.1}{T}\right)\right\} \\
& \left\{f_{\mathrm{rO}}+\left(\frac{f^{2}}{f_{\mathrm{rO}}}\right)\right\}^{-1}+0.1068 \times \exp \left(\frac{-3352.0}{T}\right) \\
& \left.\left\{f_{\mathrm{rN}}+\left(\frac{f^{2}}{f_{\mathrm{rN}}}\right)\right\}^{-1}\right],
\end{aligned}
$$

where $f_{\mathrm{r} 0}$ and $f_{\mathrm{rN}}$ are given by Eqs. (A12) and (A13), respectively.

The attenuation coefficients at 3 and $40 \mathrm{kHz}$ as a function of temperature and relative humidity estimated using Eq. (A14) are shown in Fig. A1. This figure indicates that the attenuation coefficient for ultrasound at $40 \mathrm{kHz}$ is larger than that for audible sound at $3 \mathrm{kHz}$, as expected. In addition, the attenuation coefficient depends on the temperature and humidity for both frequencies. Note that the attenuation coefficient for audible sound peaks at lower temperatures $\left(<10^{\circ} \mathrm{C}\right)$ than that for ultrasound, suggesting that the attenuation coefficient could increase with altitude for the former, while it decreases for the latter (e.g., Fig. 3, >1 km a.g.l., where $T=20.2{ }^{\circ} \mathrm{C}$ and $h_{\mathrm{r}}=76 \%$ near the surface). In contrast, the contribution of air pressure to the attenuation coefficient on the ground does not differ very much from that at an altitude of $1100 \mathrm{~m}$ a.g.l. $(\sim 900 \mathrm{hPa})$.
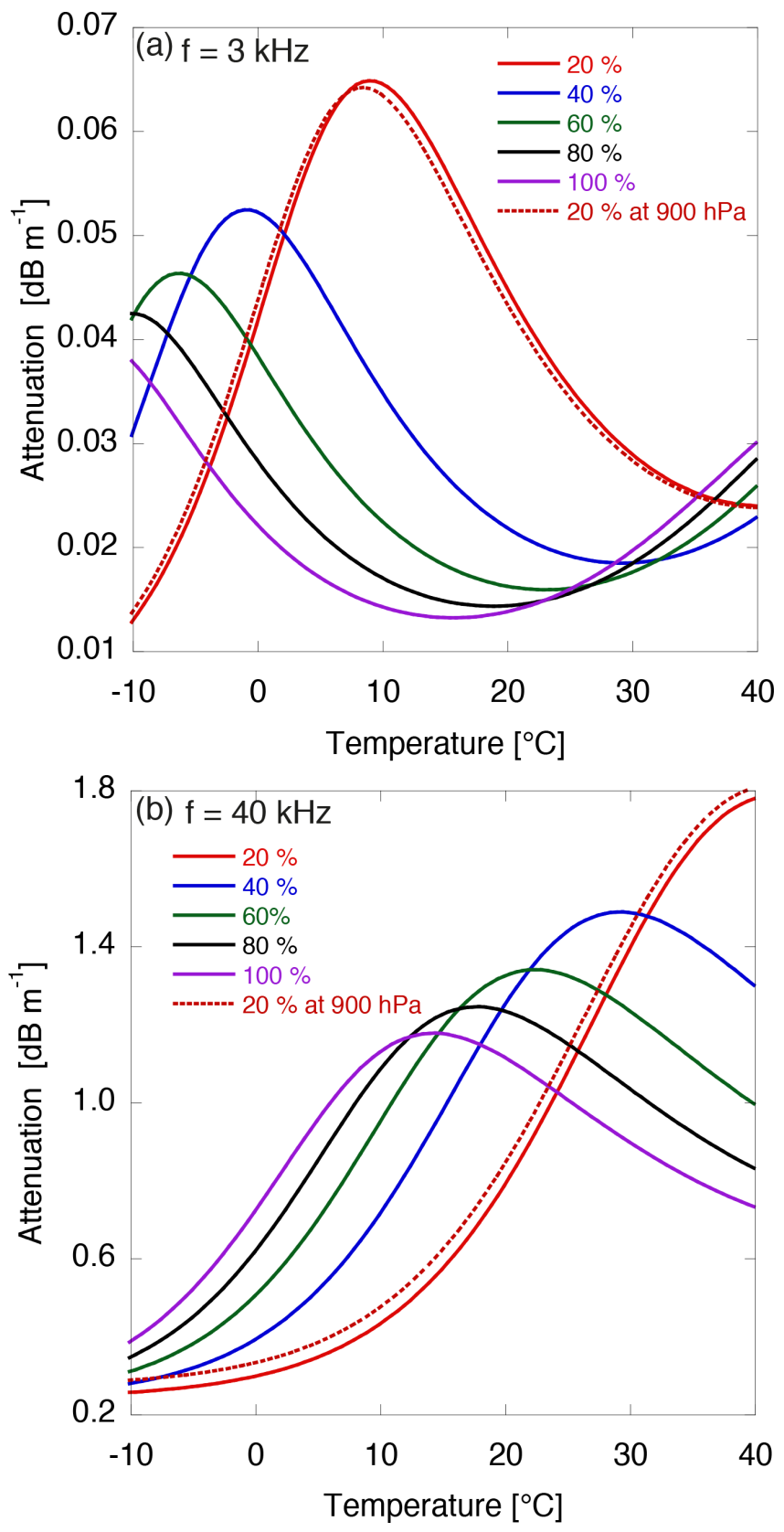

Figure A1. Simulated atmospheric-attenuation coefficients for sound at the frequencies of (a) 3 and (b) $40 \mathrm{kHz}$ as a function of the atmospheric temperature and the relative humidity at an atmospheric pressure of $1013 \mathrm{hPa}$. Results for a pressure of $900 \mathrm{hPa}$ are also plotted for a relative humidity of $20 \%$. 
Author contributions. AA conceived of the study, carried out the experiments, analyzed the data, and wrote the paper. HH performed a preliminary field test, supported the design of the PAA, and provided interpretation of the results of the experiments.

Competing interests. The authors declare that they have no conflict of interest.

Special issue statement. This article is part of the special issue "Tropospheric profiling (ISTP11) (AMT/ACP inter-journal SI)". It is a result of the 11th edition of the International Symposium on Tropospheric Profiling (ISTP), Toulouse, France, 20-24 May 2019.

Acknowledgements. The authors wish to thank Emeritus Professor Toshitaka Tsuda of Kyoto University for many helpful discussions and comments regarding the research presented and Shunsuke Hoshino of the Aerological Observatory for providing information on radiosonde measurements. The first author wishes to thank John Neuschaefer of Vaisala for offering the LAP-XM software to analyze the spectrum data, Tomoo Kamakura of the University of Electro-Communications, Shigeru Onogi of the Meteorological Instrument Centre, Noriyuki Okushima and Eiji Suzuki of Starlite Co., Ltd. and Takuo Takai for technical support, and Yoshinori Shoji, Masao Mikami, Akihide Segami, Satoru Tsunomura, and Takuya Sakashita of MRI for providing an opportunity to conduct the experiments. The authors also thank the anonymous reviewers, who made many helpful comments that improved this work substantially.

Financial support. This research has been partly supported by the JSPS KAKENHI (grant nos. 15K01273, 17H00852).

Review statement. This paper was edited by Laura Bianco and reviewed by two anonymous referees.

\section{References}

Adachi, A. and Kobayashi, T.: RHI observations of precipitation with boundary wind profiler, Munich, Am. Meteorol. Soc., 116$117,2001$.

Adachi, A., Clark, W. L., Hartten, L. M., Gage, K. S., and Kobayashi, T.: An observational study of a shallow gravity current triggered by katabatic flow, Ann. Geophys., 22, 3937-3950, https://doi.org/10.5194/angeo-22-3937-2004, 2004.

Adachi, A., Kobayashi, T., Gage, K. S., Carter, D. A., Hartten, L. M., Clark, W. L., and Fukuda, M.: Evaluation of three-beam and four-beam profiler wind measurement techniques using a five-beam wind profiler and collocated meteorological tower, J. Atmos. Ocean. Tech., 22, 1167-1180, https://doi.org/10.1175/jtech1777.1, 2005.

Adachi, T., Tsuda, T., Masuda, Y., Takami, T., Kato, S., and Fukao, S.: Effects of the acoustic and radar pulse length ratio on the accuracy of radio acoustic sounding system (RASS) temperature measurements with monochromatic acoustic pulses, Radio Sci., 28, 571-583, https://doi.org/10.1029/93RS00359, 1993.

Angevine, W. M. and Ecklund, W. L.: Errors in radio acoustic sounding of temperature, J. Atmos. Ocean. Tech., 11, 837-842, 1994.

Angevine, W. M., Ecklund, W. L., Carter, D. A., Gage, K. S., and Moran, K. P.: Improved radio acoustic sounding techniques, J. Atmos. Ocean. Tech., 11, 42-49, 1994.

Angevine, W. M., Bakwin, P. S., and Davis, K. J.: Wind profiler and RASS measurements compared with measurements from a 450-m-tall tower, J. Atmos. Ocean. Tech., 15, 818-825, 1998.

Bennett, M. B. and Blackstock, D. T.: Parametric array in air, J. Acoust. Soc. Am., 57, 562-568, https://doi.org/10.1121/1.380484, 1975.

Berktay, H. O. and Leahy, D. J.: Farfield performance of parametric transmitters, J. Acoust. Soc. Am., 55, 539-546, https://doi.org/10.1121/1.1914533, 1974.

Bianco, L. and Wilczak, J. M.: Convective boundary layer depth: Improved measurement by Doppler radar wind profiler using fuzzy logic methods, J. Atmos. Ocean. Tech., 19, 1745-1758, 2002.

Carter, D. A., Gage, K. S., Ecklund, W. L., Angevine, W. M., Johnston, P. E., Riddle, A. C., Wilson, J., and Williams, C. R.: Developments in UHF lower tropospheric wind profiling at NOAA's Aeronomy Laboratory, Radio Sci., 30, 977-1001, https://doi.org/10.1029/95RS00649, 1995.

Chandrasekhar Sarma, T. V., Narayana Rao, D., Furumoto, J., and Tsuda, T.: Development of radio acoustic sounding system (RASS) with Gadanki MST radar \&ndash; first results, Ann. Geophys., 26, 2531-2542, https://doi.org/10.5194/angeo26-2531-2008, 2008.

Ecklund, W. L., Carter, D. A., and Balsley, B. B.: A UHF wind profiler for the boundary layer: Brief description and initial results, J. Atmos. Ocean. Tech., 5, 432-441, 1988.

Fukao, S., Sato, T., Tsuda, T., Kato, S., Wakasugi, K., and Makihira, T.: The MU radar with an active phased array system: 1. Antenna and power amplifiers, Radio Sci., 20, 1155-1168, https://doi.org/10.1029/RS020i006p01155, 1985.

Gan, W.-S., Yang, J., and Kamakura, T.: A review of parametric acoustic array in air, Appl. Acoust., 73, 1211-1219, https://doi.org/10.1016/j.apacoust.2012.04.001, 2012.

Görsdorf, U. and Lehmann, V.: Enhanced accuracy of RASSmeasured temperatures due to an improved range correction, J. Atmos. Ocean. Tech., 17, 406-416, 2000.

Hashiguchi, H., Fukao, S., Moritani, Y., Wakayama, T., and Watanabe, S.: A lower troposphere radar: 1.3-GHz active phased-array type wind profiler with RASS, J. Meteorol. Soc. Jpn., 82, 915931, https://doi.org/10.2151/jmsj.2004.915, 2004.

Health .Canada: Guidelines for the safe use of ultrasound: Part II Industrial and commercial applications, Safety Code 24, available at: http://www.hc-sc.gc.ca/ewh-semt/alt_formats/hecs-sesc/ pdf/pubs/radiation/safety-code_24-securite/safety-code_ 24-securite-eng.pdf (last access: 22 October 2019), Minister of supply and services Canada, 1991.

Ishihara, M., Kato, Y., Abo, T., Kobayashi, K., and Izumikawa, Y.: Characteristics and performance of the operational wind profiler network of the Japan Meteorological Agency, J. Meteorol. 
Soc. Jpn., 84, 1085-1096, https://doi.org/10.2151/jmsj.84.1085, 2006.

ISO: 9613-1, Acoustics - Attenuation of sound during propagation outdoors - Part 1: Calculation of the absorption of sound by the atmosphere, 30 pp., available at: https://www.iso.org/standard/ 17426.html (last access: 22 October 2019), 1993.

ISO: 9613-2, Acoustics - Attenuation of sound during propagation outdoors - Part 2: General method of calculation, 18 pp., 1996.

Johnston, P. E., Hartten, L. M., Love, C. H., Carter, D. A., and Gage, K. S.: Range errors in wind profiling caused by strong reflectivity gradients, J. Atmos. Ocean. Tech., 19, 934-953, 2002.

Kizu, N., Sugidachi, T., Kobayashi, E., Hoshino, S., Shimizu, K., Maeda, R., and Fujiwara, M.: Technical characteristics and GRUAN data processing for the Meisei RS-11G and iMS-100 radiosondes, GRUAN-TD-5, GRUAN Lead Centre, 2018.

Lataitis, R. J.: Signal power for radio acoustic sounding of temperature: The effects of horizontal winds, turbulence, and vertical temperature gradients, Radio Sci., 27, 369-385, https://doi.org/10.1029/92RS00004, 1992.

Law, D. C., McLaughlin, S. A., Post, M. J., Weber, B. L., Welsh, D. C., Wolfe, D. E., and Merritt, D. A.: An electronically stabilized phased array system for shipborne atmospheric wind profiling, J. Atmos. Ocean. Tech., 19, 924-933, 2002.

Marshall, J. M., Peterson, A. M., and Barnes, A. A.: Combined Radar-Acoustic Sounding System, Appl. Opt., 11, 108-112, https://doi.org/10.1364/AO.11.000108, 1972.

Martner, B. E., Wuertz, D. B., Stankov, B. B., Strauch, R. G., Westwater, E. R., Gage, K. S., Ecklund, W. L., Martin, C. L., and Dabberdt, W. F.: An evaluation of wind profiler, RASS, and microwave radiometer performance, Bull. Am. Meteorol. Soc., 74, 599-614, 1993.

Masuda, Y.: Influence of wind and temperature on the height limit of a radio acoustic sounding system, Radio Sci., 23, 647-654, https://doi.org/10.1029/RS023i004p00647, 1988.

Matuura, N., Masuda, Y., Inuki, H., Kato, S., Fukao, S., Sato, T., and Tsuda, T.: Radio acoustic measurement of temperature profile in the troposphere and stratosphere, Nature, 323, 426-428, https://doi.org/10.1038/323426a0, 1986.

May, P. T.: Thermodynamic and vertical velocity structure of two gust fronts observed with a wind profiler/RASS during MCTEX, Mon. Weather Rev., 127, 1796-1807, 1999.

May, P. T., Strauch, R. G., and Moran, K. P.: The altitude coverage of temperature measurements using RASS with wind profiler radars, Geophys. Res. Lett., 15, 1381-1384, https://doi.org/10.1029/GL015i012p01381, 1988.
May, P. T., Moran, K. P., and Strauch, R. G.: The accuracy of RASS temperature measurements, J. Appl. Meteor., 28, 13291335, 1989.

Moran, K. P. and Strauch, R. G.: The accuracy of RASS temperature measurements corrected for vertical air motion, J. Atmos. Ocean. Tech., 11, 995-1001, 1994.

Moran, K. P., Wuertz, D. B., Strauch, R. G., Abshire, N. L., and Law, D. C.: Temperature sounding with wind profiler radars, J. Atmos. Ocean. Tech., 8, 606-608, 1991.

Neiman, P. J., May, P. T., and Shapiro, M. A.: Radio acoustic sounding system (RASS) and wind profiler observations of lowerand midtropospheric weather systems, Mon. Weather Rev., 120, 2298-2313, 1992.

Palmer, R. D., Cheong, B. L., Hoffman, M. W., Frasier, S. J., and López-Dekker, F. J.: Observations of the small-scale variability of precipitation using an imaging radar, J. Atmos. Ocean. Tech., 22, 1122-1137, https://doi.org/10.1175/JTECH1775.1, 2005.

Peters, G. and Kirtzel, H. J.: Measurements of Momentum Flux in the Boundary Layer by RASS, J. Atmos. Ocean. Tech., 11, 6375, 1994.

Peters, G., Hinzpeter, H., and Baumann, G.: Measurements of heat flux in the atmospheric boundary layer by sodar and RASS: A first attempt, Radio Sci., 20, 1555-1564, https://doi.org/10.1029/RS020i006p01555, 1985.

Westervelt, P. J.: Parametric Acoustic Array, J. Acoust. Soc. Am., 35, 535-537, https://doi.org/10.1121/1.1918525, 1963.

White, A. B., Neiman, P. J., Ralph, F. M., Kingsmill, D. E., and Persson, P. O. G.: Coastal orographic rainfall processes observed by radar during the California Land-Falling Jets Experiment, J. Hydrometeor., 4, 264-282, 2003.

WHO: Environmental Health Criteria for ultrasound, available at: http://www.inchem.org/documents/ehc/ehc/ehc22.htm (last access: 22 October 2019), Environmental Health Criteria 22, 1982.

WMO: GCOS Reference Upper-Air Network (GRUAN): Justification, requirements, siting and instrumentation options, GCOS112, WMO/TD 1379, 2007.

Wu, S., Wu, M., Huang, C., and Yang, J.: FPGA-based implementation of steerable parametric loudspeaker using fractional delay filter, Appl. Acoust., 73, 1271-1281, https://doi.org/10.1016/j.apacoust.2012.04.013, 2012.

Wulfmeyer, V., Hardesty, R. M., Turner, D. D., Behrendt, A., Cadeddu, M. P., Di Girolamo, P., Schlüssel, P., Van Baelen, J., and Zus, F.: A review of the remote sensing of lower tropospheric thermodynamic profiles and its indispensable role for the understanding and the simulation of water and energy cycles, Rev. Geophys., 53, 819-895, https://doi.org/10.1002/2014RG000476, 2015. 